\title{
The repurposed drugs suramin and quinacrine inhibit cooperatively in vitro SARS-CoV-2 3CL pro
}

Raphael J. Eberle ${ }^{1,2 \# *}$, Danilo S. Olivier ${ }^{3}$, Marcos S. Amaral ${ }^{4}$, Dieter Willbold ${ }^{2,5,6}$, Raghuvir K. Arni ${ }^{1}$, Monika A. Coronado ${ }^{1,2 \# *}$

${ }^{1}$ Multiuser Center for Biomolecular Innovation, IBILCE, Universidade Estadual Paulista (UNESP), São Jose do Rio Preto-SP, Brazil.

${ }^{2}$ Institute of Biological Information Processing (IBI-7: Structural Biochemistry), Forschungszentrum Jülich, Jülich, Germany.

${ }^{3}$ Federal University of Tocantins, Araguaína-TO, Brazil.

${ }^{4}$ Institute of Physics, Federal University of Mato Grosso do Sul, Campo Grande-MS, Brazil.

${ }^{5}$ Institut für Physikalische Biologie, Heinrich-Heine-Universität Düsseldorf, Universitätsstraße, Düsseldorf, Germany.

${ }^{6}$ JuStruct: Jülich Centre for Structural Biology, Forchungszentrum Jülich, Jülich, Germany.

"both authors contributed equally

*Corresponding authors:

Dr. Raphael J. Eberle

E-Mail: r.eberle@fz-juelich.de

Dr. Monika A. Coronado

E-Mail: m.coronado@fz-juelich.de 


\begin{abstract}
Since the first report of a new pneumonia disease in December 2019 (Wuhan, China) up to now WHO reported more than 50 million confirmed cases and more than one million losses, globally. The causative agent of COVID-19 (SARS-CoV-2) has spread worldwide resulting in a pandemic of unprecedented magnitude. To date, no clinically safe drug or vaccine is available and the development of molecules to combat SARS-CoV-2 infections is imminent. A well-known strategy to identify molecules with inhibitory potential against SARS-CoV-2 proteins is the repurposing of clinically developed drugs, e.g., anti-parasitic drugs. The results described in this study demonstrate the inhibitory potential of quinacrine and suramin against SARS-CoV-2 main protease $\left(3 \mathrm{CL}^{\text {pro }}\right)$. Quinacrine and suramin molecules present a competitive and non-competitive mode of inhibition, respectively, with $\mathrm{IC}_{50}$ and $\mathrm{K}_{\mathrm{D}}$ values in low $\mu \mathrm{M}$ range. Using docking and molecular dynamics simulations we identified a possible binding mode and the amino acids involved in these interactions. Our results suggested that suramin in combination with quinacrine showed promising synergistic efficacy to inhibit SARS-CoV-2 3CL ${ }^{\text {pro. }}$. The identification of effective, synergistic drug combinations could lead to the design of better treatments for the COVID-19 disease. Drug repositioning offers hope to the SARS-CoV-2 control.
\end{abstract}

Running title: In vitro inhibition of SARS-CoV-2 3CL pro by suramin and quinacrine.

Keywords: SARS-CoV-2, COVID-19, 3CL ${ }^{\text {pro }}$, main protease, repurposing approved drugs, suramin, quinacrine, inhibition type, substrate-binding site. 
bioRxiv preprint doi: https://doi.org/10.1101/2020 11.11.378018; this version posted November 12, 2020. The copyright holder for this preprint (which was not certified by peer review) is the author/funder, who has granted bioRxiv a license to display the preprint in perpetuity. It is made available under aCC-BY-NC-ND 4.0 International license.

\section{Introduction}

December 2019, local health authorities reported an increasing number of pneumonia cases spreading rapidly across the city of Wuhan, in the Hubei province in China. The causative agent of this disease was identified as SARS-coronavirus-2 (SARS-CoV-2) (Lu et al., 2020) and although most cases are asymptomatic or only evidence mild symptoms with good recovery rates; a small percentage of the infected patients develop more severe manifestations, such as severe pneumonia, respiratory failure, multiple organ failures and multiple cases resulting in death (Huang et al., 2020). SARS-CoV-2 has spread worldwide, leading to a coronavirus pandemic of unprecedented magnitude and the World Health Organization (WHO) declared the coronavirus disease 2019 (COVID-19) as an international public health emergency (Lai et al., 2020). Globally, more than 50 million confirmed cases resulted in over 1.2 million victims as reported by the WHO on 11th of November 2020 (World Health Organization, 2020). This staggering number is a major challenge to precarious healthcare systems, especially, in developing countries. Under these circumstances, the identification and development of safe and effective SARS-CoV-2 drugs is of high priority.

Coronoviridae forms the largest family of positive-sense single-stranded RNA viruses and is classified into four genera ( $\alpha, \beta, \gamma$, and $\delta$ ) (Nga et al., 2011). SARS-CoV, Middle East respiratory syndrome coronavirus (MERS-CoV), and SARS-CoV-2 are $\beta$-coronaviruses (de Wit et al., 2020). Analysis of the SARS-CoV-2 genome sequences revealed a higher identity to bat SARS-like coronavirus (89.1\% nucleotide similarity) (Wu et al., 2020).

The genomic RNA of coronaviruses is $\sim 30,000$ nucleotides in length and contains at least six open reading frames (ORFs) (Hussain et al., 2005; Chen et al., 2020) The first ORF (ORF 1a/b), about twothirds of the genome length, directly translates two polyproteins, ppla and pplab, so named because there is an a-1 frameshift between ORF1a and ORF1b. These polyproteins are processed by a main protease, $\mathrm{M}^{\text {pro }}$ (also known as $3 \mathrm{C}$-like protease - $3 \mathrm{CL}^{\mathrm{pro}}$ ) and, by viral papain-like proteases into 16 nonstructural proteins (NSPs). These NSPs are involved in the generation of subgenomic RNAs that encode four main structural proteins (envelope $(\mathrm{E})$, membrane $(\mathrm{M})$, spike $(\mathrm{S})$, and nucleocapsid $(\mathrm{N})$ 
proteins) and other accessory proteins (Ramajayam et al., 2011; Ren et al., 2013). Therefore, these proteases, especially $3 \mathrm{CL}^{\text {pro }}$, play vital roles in the replication process of coronaviruses.

$3 \mathrm{CL}^{\text {pro }}$ is a cysteine protease with a three-domain (domains I to III) organization and with a chymotrypsin like fold (Anand et al., 2002). Active $3 \mathrm{CL}^{\text {pro }}$ consists of a homodimer containing two protomers and the coronavirus $3 \mathrm{CL}^{\text {pro }}$ features a noncanonical Cys-His dyad located in the cleft between domains I and II (Anand et al., 2002; Anand et al., 2003; Yang et al., 2003).

The functional importance of $3 \mathrm{CL}^{\mathrm{pro}}$ in the viral life cycle combined with the absence of closely related homologues in humans, indicating that this protease is an attractive target for the development of antiviral drugs (Pillaiyar et al., 2016). So far, there are no efficacious drugs and vaccines available to combat SARS-CoV-2 infections and the bureaucratic process to approve new drugs is a very time consuming and costly process. Thus, repurposing of existing drug molecules could be a rapid alternative to combat the virus infection. The well described anti-parasitic drugs like chloroquine, quinacrine and suramin revealed anti-viral effects against SARS-Cov-2 in cell cultures (Liu et al., 2020; da Silva et al., 2020; Duan et al., 2020; Roldan et al., 2020; Touret and de Lamballerie, 2020). These three compounds have been used as antiprotozoal drugs, being that chloroquine and quinacrine are used against malaria (Hoekenga, 1955; Joy, 1999) and suramin against sleeping sickness, which is caused by trypanosomes (Steverding, 2010).

In the present study, we tested the inhibitory potentials of chloroquine, quinacrine and suramin against SARS-CoV-2 3CL pro. Quinacrine and suramin presented $\mathrm{IC}_{50}$ values $<10 \mu \mathrm{M}$ and $\mathrm{K}_{\mathrm{D}}$ values in a low $\mu \mathrm{M}$ range; however, chloroquine did not affect the SARS-CoV-2 3CL pro activity. Further experiments identified quinacrine and suramin as competitive and non-competitive inhibitor, respectively. A 1:1 combination of quinacrine and suramin decreased the $\mathrm{IC}_{50}$ value to $<500 \mathrm{nM}$. Our results indicate that quinacrine and suramin are interesting drug candidates to combat SARS-Cov-2 infections and molecular docking and molecular dynamics simulation inferred the amino acid residues responsible for the interaction between the $3 \mathrm{C}$-like protease and the molecules. 


\section{Materials and Methods}

\subsection{Cloning, expression and purification of SARS-CoV-2 3CL ${ }^{\text {pro }}$}

The codon optimized cDNA encoding SARS-CoV-2 3CL ${ }^{\text {pro }}$ (Uniprot entry: P0DTD1) was synthesized and implemented in the ampicillin resistant vector pGEX-6P-3 (BioCat GmbH, Heidelberg, Germany). The construct contains an N-terminal GST-tag and a PreScission protease cleavage site (LEFLFQGP).

SARS-CoV-2 3CL ${ }^{\text {pro }}$-pGEX-6P-3 vectors were transformed into E. coli Lemo21 (DE3) (New England BioLabs, USA) competent cells and has grown overnight at $37^{\circ} \mathrm{C}$ in LB-medium. This pre-culture was added to fresh LB-medium (Ampicillin and Chloramphenicol) and grew at $37^{\circ} \mathrm{C}$ until the cells reached an $\mathrm{OD}_{600}$ of 0.6 . Gene expression was induced with final concentration of $0.5 \mathrm{mM}$ IPTG (1 mM Rhamnose was added) and incubated for $3 \mathrm{~h}$, at $37{ }^{\circ} \mathrm{C}$ and $120 \mathrm{rpm}$. Subsequently, the culture was harvested by centrifugation $(4,000 \mathrm{rpm})$ at $5{ }^{\circ} \mathrm{C}$ for $20 \mathrm{~min}$ (Sorvall RC-5B Plus Superspeed Centrifuge, Thermo Fisher Scientific, USA; GSA rotor). The supernatant was discarded and the cells containing the recombinant SARS-CoV-2 3CL pro $G S T$ was resuspended in $50 \mathrm{mM}$ Tris- $\mathrm{HCl} \mathrm{pH} 8.0,200 \mathrm{mM} \mathrm{NaCl}$ (lysis buffer) and stored at $-20{ }^{\circ} \mathrm{C}$ for subsequent purification.

For purification, the cell-suspension was incubated on ice for $1 \mathrm{~h}$ with addition of lysozyme, subsequently it was lysed by sonication in four pulses of $30 \mathrm{~s}$ each with amplitude of $30 \%$ interspersed by intervals of $10 \mathrm{~s}$. The crude cell extract obtained was centrifuged (7,000 rpm for 90 $\min$ at $6{ }^{\circ} \mathrm{C}$ ). The supernatant containing SARS-CoV-2 3CL pro $\mathrm{GST}$ was loaded onto a GSHSepharose matrix which was previously extensively washed with the lysis buffer and was extensively washed with the same buffer. The protein was eluted with the same buffer plus addition of $10 \mathrm{mM} \mathrm{GSH}$. The eluted fractions were concentrated and dialyzed against PreScission protease cleavage buffer (50 mM Tris pH 7.0, $200 \mathrm{mM} \mathrm{NaCl,} 1 \mathrm{mM}$ DTT and $1 \mathrm{mM}$ EDTA). PreScission protease was used to cleave the GST-tag from the SARS-CoV-2 $3 \mathrm{CL}^{\text {pro }}$ GST fused protein. For $100 \mu \mathrm{g}$ target protein concentration, $10 \mu \mathrm{g}$ PreScission protease was added and the sample was 
incubated for $36 \mathrm{~h}$ at $4{ }^{\circ} \mathrm{C}$. Separation of the target protein, the GST-tag and the PreScission protease was achieved using GSH-Sepharose. Further, to remove aggregated fraction, size exclusion chromatography was used (Superdex 200 10/300 GL GE Healthcare, USA), the column was equilibrated with $20 \mathrm{mM}$ Tris-HCL pH 8.0, $150 \mathrm{mM} \mathrm{NaCl}$. Sample purity after each purification step was assessed by $15 \%$ SDS-PAGE gels. The corresponding protein fraction was concentrated up to $2 \mathrm{mg} / \mathrm{ml}$ and stored at $-20^{\circ} \mathrm{C}$.

\subsection{Activity assay of SARS-CoV-2 3CL ${ }^{\text {pro }}$}

SARS-CoV-2 $3 \mathrm{CL}^{\text {pro }}$ activity assay was performed as described earlier using a fluorogenic substrate DABCYL-KTSAVLQ $\downarrow$ SGFRKME-EDANS (Bachem, Switzerland) in a buffer containing $20 \mathrm{mM}$ Tris pH 7.2, $200 \mathrm{mM} \mathrm{NaCl}, 1$ mM EDTA and $1 \mathrm{mM}$ TCEP (Zhang et al., 2020a; Zhang et al., 2020b; Ma et al., 2020). The reaction mixture was pipetted in a Corning 96-Well plate (Sigma Aldrich) consisting of $0.5 \mu \mathrm{M}$ protein and the assay was initiated with the addition of the substrate at a final concentration of $50 \mu \mathrm{M}$. The fluorescence intensities were measured at $60 \mathrm{~s}$ intervals over 30 minutes using an Infinite 200 PRO plate reader (Tecan, Männedorf, Switzerland). The temperature was set to $37^{\circ} \mathrm{C}$. The excitation and emission wavelengths were $360 \mathrm{~nm}$ and 460 $\mathrm{nm}$, respectively. For $\mathrm{K}_{\mathrm{M}}$ and $\mathrm{V}_{\max }$ measurements, the procedure was followed as described previously (Ma et al., 2020). A substrate concentration from 0 to $200 \mu \mathrm{M}$ was applied. The initial velocity of the proteolytic activity was calculated by linear regression for the first 15 minutes of the kinetic progress curves. The initial velocity was plotted against the substrate concentration with the classic Michaelis-Menten equation using GraphPad Prism ${ }^{5}$ software and $\mathrm{K}_{\mathrm{cat}}$ was obtained using the equation (1):

$$
\mathrm{K}_{\mathrm{cat}}=\mathrm{V}_{\mathrm{max}} /[\mathrm{E}]
$$

while $V_{\max }$ is the experimental determined maximal velocity and $[\mathrm{E}]$ is the enzyme concentration in the experiment (Berg et al., 2002). All measurements were performed in triplicate and data are presented as mean \pm SD. 


\subsection{Inhibition assay of SARS-CoV-2 3CL ${ }^{\text {pro }}$}

Inhibition of SARS-CoV-2 $3 \mathrm{CL}^{\text {pro }}$ activity by chloroquine, quinacrine and suramin was investigated using the activity assay described above. $10 \mu \mathrm{M}$ of the compounds was used for a preliminary screening test. For the final inhibition assays $0.5 \mu \mathrm{M}$ of the protein was incubated with 0-100 $\mu \mathrm{M}$ suramin and 0-150 $\mu \mathrm{M}$ quinacrine, chloroquine did not show a satisfactory inhibitory effect, therefore it was excluded from the studies. The mixtures were incubated for 30 minutes at RT. When the substrate with a final concentration of $50 \mu \mathrm{M}$ was added to the mixture, the fluorescence intensities were measured at $60 \mathrm{~s}$ intervals over 30 minutes using an Infinite $200 \mathrm{PRO}$ plate reader (Tecan, Männedorf, Switzerland). The temperature was set to $37^{\circ} \mathrm{C}$. The excitation and emission wavelengths were $360 \mathrm{~nm}$ and $460 \mathrm{~nm}$, respectively. Inhibition assays were performed as triplicates.

For the quinacrine and suramin combination test, a 1:1 stock solution of the molecules was prepared and $0.5 \mu \mathrm{M}$ of the protein was incubated with $0-75 \mu \mathrm{M}$ of the combined molecules (quinacrine and suramin).

The $\mathrm{IC}_{50}$ value was calculated by plotting the initial velocity against various concentrations of the combined molecules using a dose-response curve in GraphPad Prism ${ }^{5}$ software. All measurements were performed in triplicate and data are presented as mean $\pm \mathrm{SD}$.

\subsection{Determination of inhibition mode and inhibitory constant}

The mode of inhibition was determined using different final concentrations of the inhibitors and substrate. Briefly, SARS-CoV-2 $3 \mathrm{CL}^{\text {pro }}$ at $0.5 \mu \mathrm{M}$ was incubated with the inhibitor at different concentrations for 30 minutes at RT. Subsequently, the reaction was initiated by the addition of the corresponding concentration series of the substrate. The data analysis was performed using a Lineweaver-Burk plot, therefore the reciprocal of velocity $(1 / \mathrm{V})$ vs. the reciprocal of the substrate concentration (1/[S]) was compared (Motulsky and Christopoulos, 2004; Roy et al., 2017). All 
measurements were performed in triplicate and data are presented as mean \pm SD. The inhibitory constant $\left(\mathrm{K}_{\mathrm{i}}\right)$ was obtained using equation (2):

$$
\mathrm{IC}_{50} /\left(\left([\mathrm{S}] / \mathrm{K}_{\mathrm{M}}\right)+1\right)
$$

while $\mathrm{IC}_{50}$ and $\mathrm{K}_{\mathrm{M}}$ were determined as described before and $[\mathrm{S}]$ is the concentration of substrate used in the experiments (Wu et al., 2014).

\subsection{Determination of dissociation constant using fluorescence spectroscopy}

The intrinsic Trp fluorescence of SARS-CoV-2 3CL pro was measured under the influence of quinacrine and suramin, based on this experiment the dissociation constant between the protein and the ligands could be determined (Coronado et al., 2018). Briefly, protein sample was in $25 \mathrm{mM}$ Tris- $\mathrm{HCl} \mathrm{pH} 8.0,150 \mathrm{mM} \mathrm{NaCl}$ with a final concentration of $10 \mu \mathrm{M} / 50 \mu$. The protein solution within the cuvette $(1 \mathrm{~cm}$ path length) was titrated stepwise with a molecule stock solution 0-48 $\mu \mathrm{M}$ of quinacrine or suramin (to avoid protein dilution the molecule stock solution was treated with the same protein concentration $-10 \mu \mathrm{M}$ protein $+500 \mu \mathrm{M}$ molecule stock). A measurement was conducted following each titration. The quenching of the protease fluorescence, $\Delta \mathrm{F}\left(\mathrm{F}_{\max }-\mathrm{F}\right)$, at 330 $\mathrm{nm}$ of each titration point was used for fitting a saturation binding curve using a nonlinear leastsquares fit procedure which has been discussed in detail elsewhere (Johnson and Frasier, 1985) based on equation (3) (Shaikh et al., 2007):

$$
\mathrm{Y}=\mathrm{B}_{\max }[\mathrm{Q}] / \mathrm{K}_{\mathrm{D}}+[\mathrm{Q}]
$$

where, [Q] is the ligand concentration in solution, acting as a quencher, $\mathrm{y}$ is the specific binding derived by measuring fluorescence intensity, $\mathrm{B}_{\max }$ is the maximum amount of the protease-ligand complex at saturation of the ligand and $\mathrm{K}_{\mathrm{D}}$ is the equilibrium dissociation constant. The percentage of bound protease, i.e. $y$, derived from the fluorescence intensity maximum, is plotted against the ligand concentration. Additionally, the data were fitted with a modified Hill equation obtaining the following relation (4) (Wang et al., 2015; Ahumada et al., 2017): 


$$
\log \left(\mathrm{F}-\mathrm{F}_{\min }\right) /(\mathrm{F})=\mathrm{m} \log \mathrm{K}_{\mathrm{D}}+\mathrm{n} \log [\mathrm{Q}]
$$

where, $F_{\min }$ is the minimal fluorescence intensity in the presence of the ligand, $\mathrm{K}_{\mathrm{D}}$ is the equilibrium constant for the protein-ligand complex. The "binding constant" $\mathrm{K}$ is defined as the reciprocal of $K_{D}$.

\subsection{Circular dichroism (CD) spectroscopy}

CD measurements were carried out with a Jasco J-1100 Spectropolarimeter (Jasco, Germany). Far-UV spectra were measured in 190 to $260 \mathrm{~nm}$ using a protein concentration of four $\mu \mathrm{M}$ in 20 $\mathrm{mM} \mathrm{K} \mathrm{HPO}_{4} / \mathrm{KH}_{2} \mathrm{PO}_{4} \mathrm{pH}$ 7.5. Cells of one mm path length were used for the measurements; 15 repeat scans were obtained for each sample and five scans were conducted to establish the respective baselines. The averaged baseline spectrum was subtracted from the averaged sample spectrum. The results are presented as molar ellipticity $[\theta]$, according to the equation (5):

$$
[\theta]_{\lambda}=\theta /(\mathrm{c} * 0.001 * 1 * \mathrm{n})
$$

where $\theta$ is the ellipticity measured at the wavelength $\lambda(\mathrm{deg}), \mathrm{c}$ is the protein concentration $(\mathrm{mol} / \mathrm{L}), 0.001$ the cell path length $(\mathrm{cm})$ and $\mathrm{n}$ the number of amino acids. The results were analyzed and the secondary structure content was determined using the CDpro software package (Sreerama and Woody, 2000).

\subsection{Systems information, molecular docking and ligand parameterization}

The 3D model of SARS-CoV-2 $3 \mathrm{CL}^{\text {pro }}$ was obtained from the PDB database (PDB entry: $6 \mathrm{M} 2 \mathrm{Q})$. The protonation state of the amino acid side chain was set to $\mathrm{pH} 7.4$ using web-server $\mathrm{H}++$ (Gordon et al., 2005), placed in a water box, neutralized and followed by a $200 \mathrm{~ns}$ molecular dynamics (MD) simulation and the representative structure was obtained by clustering analysis. Molecular docking was used to select the best pose for the ligand-protein interaction using 
bioRxiv preprint doi: https://doi.org/10.1101/2020 11.11.378018; this version posted November 12, 2020. The copyright holder for this preprint (which was not certified by peer review) is the author/funder, who has granted bioRxiv a license to display the preprint in perpetuity. It is made available under aCC-BY-NC-ND 4.0 International license.

Autodock Vina program (Trott and Olson, 2010). A grid box was defined for docking the molecule (quinacrine) near the active site and for docking in an allosteric site (suramin). These calculations were performed with the scoring function of the program that ranked several poses for each ligand. The best pose of each ligand was chosen to prepare the $3 \mathrm{CL}^{\mathrm{pro}}$-quinacrine and -suramin complexes.

Ligands were parameterized using Gaussian 16 (Frisch et al., 2016) at the level of theory HF/6$31 \mathrm{G}^{*}$ to optimize their geometry and calculate their electrostatic potentials. Restrained electrostatic potential (RESP) charges were determined using antechamber (Wang et al., 2006), while the general amber force field (GAFF) (Wang et al., 2004) was used for the missing parameters.

\subsection{Simulation setup}

All the molecular dynamics simulations were carried out using the Amber18 (Case et al., 2018) software package and the FF19SB (Tian et al., 2020) force field was used to describe the protein atoms interactions, while GAFF and RESP charges describe the quinacrine and suramin molecules. The systems were solvated in an octahedral box of TIP3P water molecules with at least $10 \AA$ distance from any solvent atoms between the solute's in each direction and the system was neutralized when necessary. Initially, energy minimization was performed in two steps to remove poor contacts from the initial structures. First, the protein/complex was constrained (force constant of $50.0 \mathrm{kcal} / \mathrm{mol} . \AA^{2}$ ) and minimized using 5,000 steepest descent steps followed by 5,000 conjugate gradient steps and by a 10,000 steps unconstrained energy minimization round. The system was slowly heated from 0 to $298 \mathrm{~K}$ for 500 ps under constant atom number, volume and temperature (NVT) ensemble, while the protein was restrained with a force constant of $25 \mathrm{kcal} / \mathrm{mol} . \AA^{2}$. After the heating process, the equilibrium stage was performed using constant atoms number, pressure and temperature (NpT) ensemble for $5 \mathrm{~ns}$. Finally, the simulation run was performed for $200 \mathrm{~ns}$ (single protein) and $300 \mathrm{~ns}$ (complexes) without any restraints and under NVT ensemble and, the constant temperature and pressure (1 atm) were controlled by Langevin coupling. Long-range electrostatic interaction was calculated by the particle-mesh Ewald method (PME) (Darden et al., 
1993) with 8 A cutoff. The Shake constraints were applied to all bonds involving hydrogen atoms to allow a 2-fs dynamics time step.

\subsection{Molecular dynamics analysis}

The CPPTRAJ9 program of AmberTools19 (Case et al., 2005) was used to analyze the MD simulations. Root mean square deviation (RMSD) and the radius of gyration $(\mathrm{Rg})$ of $\mathrm{C} \alpha$ were calculated to determine the system quality and stability and to determine the equilibration and convergence of the systems. Protein flexibility was calculated by the root mean square fluctuation (RMSF) for all $\mathrm{C} \alpha$ atoms, residue-by-residue over the equilibrated trajectories.

Clustering analysis was performed with the k-means method ranging from 2 to 6 and to access the quality of clustering the DBI values and silhouette analyses was used.

The interaction energy was calculated using the generalized Born (GB)-Neck2 (Nguyen et al., 2013) implicit solvent model (igb $=8$ ). Molecular mechanics/generalized Born surface area (MM/GBSA) energy was computed between the protein and the ligand in a stable regime comprising the last $50 \mathrm{~ns}$ of the MD simulation, stripping all the solvent and ions. The web version of POCASA 1.1 was used to determine the volume of the active site pocket after MD simulations (Yu et al., 2010).

\subsection{Statistical analysis}

The significance of the inhibition assays and fluorescence spectroscopy experiments were evaluated by a one-way analysis of variance (ANOVA) followed by Bonferroni post hoc test. Differences were considered significant when a $P$ value was less than 0.05 (Zhang et al., 1999) All statistical analyses were performed with GraphPad Prism software version 5 (San Diego, CA, USA). 


\section{Results and Discussion}

\subsection{Expression and Purification of SARS-CoV-2 3CL}

SARS-CoV-2 3CL pro_GST fusion protein was expressed in E. coli Lemo21 (DE3) cells and purified using a GSH-Sepharose column (Supplementary Fig. S1A). The relevant protein fractions were concentrated and prepared for PreScission protease cleavage to remove the GST-tag. The SDS gel (Supplementary Fig. S1B and S1C) indicate the cleavage efficiency and the purity of 3CL ${ }^{\text {pro }}$. The pure protein was concentrated and applied onto a Superdex 200 10/300 GL size exclusion chromatography (GE Healthcare) to remove aggregated protein species (Supplementary Fig. S1D). CD spectroscopy of $3 \mathrm{CL}^{\text {pro }}$ indicated that the protein is correctly folded after purification process and GST-cleavage. Deconvolution of the CD data using the software CDpro (Sreerama and Woody, 2000) showed that the protein secondary structure contains around 28\% $\alpha$-helices and $23 \%$ $\beta$-strands. Which is in good agreements with data from the crystal structure (PDB entry: 6M2Q) which contain 25\% $\alpha$-helices and 28\% $\beta$-strands (Supplementary Fig. S1E).

\subsection{Activity assay of SARS-CoV-2 3CL pro}

The SARS-CoV-2 3CL ${ }^{\text {pro }}$ activity was investigated using an assay procedure described earlier (Zhang et al., 2020a; Zhang et al., 2020b; Ma et al., 2020) and DABCYL-KTSAVLQ/SGFRKMEEDANS (Bachem, Switzerland) was used as substrate. Activity assays were performed to obtain the kinetic key values $\mathrm{V}_{\max }, \mathrm{K}_{\mathrm{M}}$ and $\mathrm{K}_{\text {cat }}$. A standard curve was generated converting the relative fluorescence unit (RFU) to the amount of cleaved substrate $(\mu \mathrm{M})$ (Supplementary Fig. S2A). In the next step, enzymatic activity of the protease was characterized by measuring $V_{\max }$ and $\mathrm{K}_{\mathrm{M}}$ values; $0.5 \mu \mathrm{M}$ of the protease was mixed with various concentrations of the substrate $(0-200 \mu \mathrm{M})$. The initial velocity was measured and plotted against the substrate concentration. Curve fitting with Michaelis-Menten equation resulted in the best fitting values of $\mathrm{K}_{\mathrm{M}}$ and $\mathrm{V}_{\max }$ as $25.47 \pm 3.43 \mu \mathrm{M}$ and $47.52 \pm 2.91 \mu \mathrm{M} / \mathrm{s}$, respectively (Supplementary Fig. S2B). The calculated $\mathrm{K}_{\mathrm{cat}} / \mathrm{K}_{\mathrm{M}}$ was 
bioRxiv preprint doi: https://doi org/10.1101/2020.11.11.378018; this version posted November $12,2020$. The copyright holder for this preprint (which was not certified by peer review) is the author/funder, who has granted bioRxiv a license to display the preprint in perpetuity. It is made available under aCC-BY-NC-ND 4.0 International license.

3,731.21 s $\mathrm{s}^{-1} \mathrm{M}^{-1}$ which is like the previously reported values $3,4261.1 \mathrm{~s}^{-1} \mathrm{M}^{-1}$ and $5,624 \mathrm{~s}^{-1} \mathrm{M}^{-1}$ (Zhang et al., 2020a; Ma et al., 2020).

\subsection{Inhibition assay of chloroquine, quinacrine and suramin against SARS-CoV-2 $3 C^{\text {pro }}$}

A primary inhibition test of the three antiparasitic compounds chloroquine, quinacrine and suramin $(10 \mu \mathrm{M})$ was performed against SARS-CoV-2 3CL pro to screen the best inhibitor against the virus protease (Fig. 1).

Figure 1

Fig. 1. Preliminary inhibition tests of chloroquine, quinacrine and suramin against SARS-CoV-2 3CL ${ }^{\text {pro. }}$ Quinacrine and suramin inhibit the virus protease activity by more than $60 \%$. Contrary, chloroquine shows not relevant inhibition, just about $10 \%$. The blue box shows the molecular structures of (A) Chloroquine, (B) Quinacrine and (C) Suramin.

The primary inhibition tests showed a strong effect of quinacrine and suramin against SARSCoV-2 $3 \mathrm{CL}^{\text {pro }}$ activity. In contrast, chloroquine has a weak effect on $3 \mathrm{CL}^{\text {pro }}$ proteolytic activity. Suramin and quinacrine possess an anti-viral effect against SARS-CoV-2 in cell culture (da Silva et al., 2020; Duan et al., 2020; Roldan et al., 2020; Touret and de Lamballerie, 2020), however, the target protein of both molecules in the viral replication process was not identified. Based on the primary inhibition results, quinacrine and suramin were further investigated regarding their inhibitory potential, and our results demonstrate that suramin and quinacrine have an inhibitory effect against the 3CL protease of SARS-CoV-2 (Figures 2 and 3, respectively).

Figure 2

Fig. 2. Inhibition effect and inhibition mode of quinacrine over SARS-CoV-2 3CL ${ }^{\text {pro }}$. (A) 3D representation of the $3 \mathrm{CL}^{\text {pro }}$ quinacrine complex (3CL pro in Ribbon and quinacrine in Sticks). $3 \mathrm{CL}^{\text {pro }}$ monomers are colored in green and blue, and quinacrine in orange. Normalized activity and inhibition of the virus proteases and, Lineweaver-Burk plots to determine the inhibition mode are presented. $[\mathrm{S}]$ is the substrate concentration; $\mathrm{v}$ is the initial reaction rate. (B) Normalized activity and inhibition of SARS-CoV-2 $3 \mathrm{CL}^{\text {pro }}$ under quinacrine influence. $(\mathbf{C})$ Lineweaver-Burk plot for quinacrine inhibition of SARS-CoV-2 3CL ${ }^{\text {pro }}$.

Quinacrine inhibit the protease activity $100 \%$ at a concentration of $150 \mu \mathrm{M}$ (Fig. 2B) and suramin at $100 \mu \mathrm{M}$ (Fig. 3B). Quinacrine has a calculated $\mathrm{IC}_{50}$ value of $7.8 \pm 0.9 \mu \mathrm{M}$ (Table 1 and Supplementary Fig. S3A). Further experiments identified quinacrine as a competitive inhibitor of the $3 \mathrm{CL}^{\text {pro }}$ (Fig. 2C), it means that the molecule interacts directly with amino acid residues located 
in the active site and/or with the substrate-binding site. In contrast, suramin acts as a noncompetitive inhibitor (Fig. 3), showing a type of allosteric inhibition.

Figure 3

Fig. 3. Inhibition effect and inhibition mode of suramin over SARS-CoV-2 3CL $\mathbf{L}^{\text {pro }}$. (A) 3D representation of the $3 \mathrm{CL}^{\mathrm{pro}}$-suramin complex (3CL pro in Ribbon and suramin in Sticks). 3CL pro monomers are colored in green and blue and suramin in orange. Normalized activity and inhibition of the virus proteases and, Lineweaver-Burk plots to determine the inhibition mode are presented. $[S]$ is the substrate concentration; $v$ is the initial reaction rate. (B) Normalized activity and inhibition of SARS-CoV-2 $3 \mathrm{CL}^{\text {pro }}$ under suramin influence. (C) Lineweaver-Burk plot for suramin inhibition of SARS-CoV-2 3CL ${ }^{\text {pro }}$.

The potency of suramin in inhibiting $3 \mathrm{CL}^{\text {pro }}$ was calculated and demonstrated an $\mathrm{IC}_{50}$ value of

\section{$6.3 \pm 0.8 \mu \mathrm{M}$ (Table 1 and Supplementary Fig. S3B).}

The $\mathrm{IC}_{50}$ values of both molecules are in a concentration range with other repurposed drug molecules, which also demonstrate inhibitory effect against SARS-CoV-2 3CL ${ }^{\text {pro }}$, for example; boceprevir has an $\mathrm{IC}_{50}$ value of $4.14 \mu \mathrm{M}$ (Ma et al., 2020), menadione presents $\mathrm{IC}_{50}$ value of 7.9 $\mu \mathrm{M}$ (He et al., 2020) and disulfiram has an $\mathrm{IC}_{50}$ of $9.35 \mu \mathrm{M}$ (Jin et al., 2020).

Table 1. Summary of the SARS-CoV-2 3CL $L^{\text {pro }}$ inhibition experiments by quinacrine and suramin.

\begin{tabular}{llll}
\hline Molecule & $\mathrm{IC}_{50}[\mu \mathrm{M}]$ & $\mathrm{K}_{\mathrm{i}}[\mu \mathrm{M}]$ & Inhibition type \\
\hline Quinacrine & $7.8 \pm 0.9$ & $1.6 \pm 0.4$ & competitive \\
Suramin & $6.3 \pm 0.8$ & $1.3 \pm 0.4$ & non-competitive \\
\hline
\end{tabular}

\subsection{Investigation of SARS-CoV-2 3CL ${ }^{\text {pro }}$ with suramin and quinacrine using fluorescence}

\section{spectroscopy}

To confirm the viability of the assay, fluorescence spectra from the intrinsic tryptophan $(\operatorname{Trp})$ of the SARS-CoV-2 $3 \mathrm{CL}^{\text {pro }}$ with the inhibitor molecules were investigated. The fluorescence changes of Trp can reflect environmental variation of the protein and the decreased Trp emission intensity confirmed the complex formation between the protease and the inhibitory molecules. Based on the quenching of the protease fluorescence of each titration point, the dissociation constant $\left(\mathrm{K}_{\mathrm{D}}\right)$ could be determined for each molecule (suramin and quinacrine) (Supplementary Fig. S4). 
Table 2. Summary of the SARS-CoV-2 3CL pro in complex with

quinacrine and suramin.

\begin{tabular}{lll}
\hline Molecule & $\mathrm{K}_{\mathrm{D}}[\mu \mathrm{M}]$ & Excitation shift \\
\hline Quinacrine & $6.0 \pm 1.8$ & blue edge excitation shift \\
Suramin & $4.5 \pm 1.2$ & red edge excitation shift
\end{tabular}

Table 2 describe the $K_{D}$ value of the suramin interaction with SARS-CoV-2 3CL ${ }^{\text {pro }}(4.5 \pm 1.2$ $\mu \mathrm{M})$ with slight increase for quinacrine $(6.0 \pm 1.8 \mu \mathrm{M})$. Interestingly, the protein interaction with suramin or quinacrine induce a different type of excitation shift of the protein tryptophans. Suramin interaction induces a conformational change in the protein structure, which was demonstrated by a red edge excitation shift (REES) of about $30 \mathrm{~nm}$ (330 to $360 \mathrm{~nm}$ ) (Supplementary Fig. S4A). REES is defined through increasing interactions between the fluorophore (Trp) and the surrounding solvent in the ground and excited state (Catici et al., 2016). On the contrary, the quinacrine interaction induced a blue edge excitation shift (BEES) of around $10 \mathrm{~nm}$ (330 to $320 \mathrm{~nm}$ ) (Supplementary Fig. S4C). Through BEES, the environment hydrophobicity of the Trp residue increases significantly (Möller and Denicola, 2002).

\subsection{Docking and molecular dynamic simulations of suramin and quinacrine with SARS-CoV-}

\section{$23 \mathrm{CL}^{\text {pro }}$ structure}

The atomic coordinates from SARS-CoV-2 3CL pro (PDB entry: 6M2Q) was used as initial model. Cluster analysis of the MD simulations demonstrated that cluster \#0 showed the best results with representativeness of over $86.1 \%$ of the whole simulation time and the selected structure appeared during the simulation around 169 ns (Supplementary Fig. S5). SARS-CoV-2 3CL ${ }^{\text {pro }}$ is a homodimer with the catalytical dyad His41 and Cys145 (Zhang et al., 2020a). Dimerization of the protease is necessary for catalytic activity; the interaction of each protomer N-terminal Ser1 with Glu166 of the other protomer stabilizes the shape of the S1 pocket, which is important for the binding of the substrate (Anand et al., 2002). Chen et al. 2006 suggested that only one protomer of the SARS-CoV $3 C^{\text {pro }}$ dimer is active (Chen et al., 2006). Interestingly, after the initial MD simulations of SARS-CoV-2 3CL pro dimer (Supplementary Fig. S6), one protomer active site 
bioRxiv preprint doi: https://doi org/10.1101/2020.11.11.378018; this version posted November $12,2020$. The copyright holder for this preprint (which was not certified by peer review) is the author/funder, who has granted bioRxiv a license to display the preprint in perpetuity. It is made available under aCC-BY-NC-ND 4.0 International license.

collapsed and, the volume of the pocket decreased by around twofold, from 261 to $142 \AA^{3}$ compared to the active site of the other protomer. The main difference observed between the two protomers succeeding the MD simulation was the interaction between the C-terminal Gln306 and Ile152 of the same protomer. A hydrogen bond was observed between NE2 of Gln306 and the backbone oxygen of Ile152 (Supplementary Fig. S7). We assume that this interaction in addition to the already described (Glu166 with Ser1) stabilizes the active site. To conceive the molecular binding modes of the inhibitory molecules, theoretical investigations through docking and molecular dynamics simulations were carried out. The interactions between SARS-CoV-2 3CL ${ }^{\text {pro }}$ in complex with quinacrine or suramin were analyzed to predict their binding mode. Quinacrine was docked in both protease active sites (as competitive inhibitor) and suramin (as non-competitive inhibitor) in a region with strong positive charges on the protein surface, as suramin is a highly negatively charged molecule (Burch and Ashburn, 1951). Subsequent MD simulations demonstrated a stable system for a period of $300 \mathrm{~ns}$ (Supplementary Fig. S8 and S9). The binding assessment of the ligands to the protease was observed using a residue-wise decomposition of the binding energy received from the MD simulations. Table 3 and Fig. 4 illustrate the $3 C^{\text {pro }}$ amino acid residues contribution to the binding energy in the active site that interact with quinacrine. The interactions between quinacrine and the protease are stabilized by two hydrogen bonds (H-bond), which are mediated by donor and acceptor atoms of Met165 and Gln189 (Table 4). His41, Met49, Val186, Arg188 and Gln194 interact with quinacrine by hydrophobic interactions (Table 3 and Fig. 4).

Figure 4

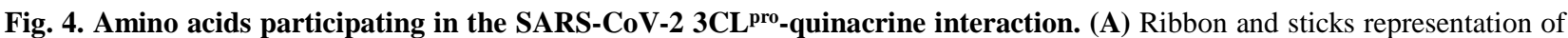
the SARS-CoV-2 3CL pro-quinacrine complex after MD simulation. (B) Decomposition of the binding energy of SARS-CoV-2 $3 \mathrm{CL}^{\text {pro }}$-quinacrine complex. Arrows label protomer A (turquoise) and protomer B (gold). (C) SARS-CoV-2 $3 \mathrm{CL}^{\text {pro }}$ amino acids involved in the interaction with quinacrine based on MD simulations. (D) Quinacrine interaction in the protease substrate-binding and active site. The substrate-binding subsites are highlighted: green S1 ; gold S1; red S2 and blue S3.

Fig. 5 shows the amino acid residues involved in the interaction between $3 \mathrm{CL}^{\text {pro }}$ and suramin, Tables 3 and 4 summarize the H-bonds and hydrophobic interactions. The interactions that stabilize the protease-suramin complex are mediated by six H-bonds that are formed by Lys12, Lys97, 
Lys100, Tyr101 and Phe103. Additionally, the ligand is stabilized by hydrophobic interactions with the residues: Lys97, Lys100, Lys102, Phe103, Val104 and Arg105 (Table 3).

\section{Figure 5}

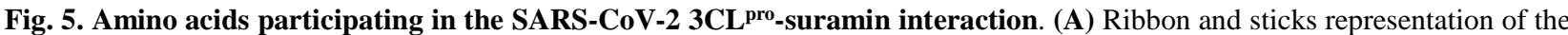

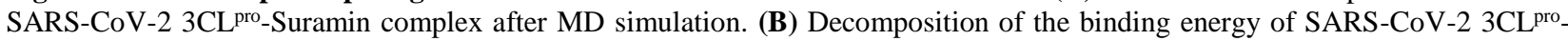
suramin complex. Arrows label protomer A (turquoise) and protomer B (gold). (C) SARS-CoV-2 3CL ${ }^{\text {pro }}$ amino acids involved in the interaction with Suramin based on MD simulations.

As a competitive inhibitor of SARS-CoV-2 $3 \mathrm{CL}^{\text {pro }}$, quinacrine interacts through hydrophobic interaction with His41 of the protease catalytic dyad, blocking the entrance to the active site.

Table 3. SARS-CoV-2 3CL ${ }^{\text {pro }}$ Residues involved in forming H-bonds and hydrophobic contacts with quinacrine and suramin.

\begin{tabular}{lll}
\hline Ligand & Interacting Residues & \\
\hline \multirow{3}{*}{ Quinacrine } & Met165, Gln189 & His41, Met49, Val186, Asp187, \\
& & Arg188, Gln194 \\
\multirow{2}{*}{ Suramin } & Lys12, Lys97, Lys100, & Lys97, Lys100, Lys102, Phe103, \\
& Tyr101, Phe103 & Val104, Arg105 \\
\hline
\end{tabular}

On the contrary, suramin is not directly interacting with the active site residues and our results suggested that suramin interact with the protein allosterically changing the catalytic site conformation, thus preventing the substrate entry.

Table 4. Atoms involved in the H-Bond interaction between SARS-CoV-2 3CL $L^{\text {pro }}$ and inhibitors.

\begin{tabular}{|c|c|c|c|c|}
\hline Ligand & Residue & Atom (Ligand) & H-bond Donor/Acceptor & Distance $[\AA]$ \\
\hline \multirow[t]{2}{*}{ Quinacrine } & Met165 & & & \\
\hline & $\begin{array}{l}\text { (Side chain) CE } \\
\text { GIn189 }\end{array}$ & CL1 & C-H- - -CL & 3.6 \\
\hline \multirow[t]{7}{*}{ Suramin } & $\begin{array}{l}\text { (Side chain) OE1 } \\
\text { Lys } 12\end{array}$ & N3 & O- - -H-N & 2.7 \\
\hline & $\begin{array}{l}\text { (Side chain) NZ } \\
\text { Lys97 }\end{array}$ & $\mathrm{O} 18$ & N-H- - -O & 2.8 \\
\hline & $\begin{array}{l}\text { (Side chain) NZ } \\
\text { Lys } 100\end{array}$ & $\mathrm{O} 14$ & N-H- - -O & 2.9 \\
\hline & $\begin{array}{l}\text { (Backbone) N } \\
\text { Tyr101 }\end{array}$ & $\mathrm{O} 13$ & N-H- - -O & 3.6 \\
\hline & $\begin{array}{l}\text { (Backbone) O } \\
\text { Phe103 }\end{array}$ & N3 & O- - -H-N & 3.4 \\
\hline & (Backbone) $\mathrm{N}$ & O11 & N-H- - -O & 2.8 \\
\hline & (Backbone) O & N1 & O- - -H-N & 3.5 \\
\hline
\end{tabular}


An important task is the suitability of the inhibitor to the binding areas so that covalent inhibition occurs (Pettinger et al., 2017). Therefore, the nucleophilicity of the amino acid residues in the target and electrophilic groups in the drug need to be considered (Way, 2000). The relative nucleophilicity of the amino acid residues in their neutral states are given in the order of Cys $(1)>$ His $\left(10^{-2}\right)>$ Met $\left(10^{-3}\right)>$ Lys, Ser $\left(10^{-5}\right)>$ Thr and Tyr $\left(10^{-6}\right)$ (Way, 2000; Pettinger et al., 2017). This is one of the reasons why many of the covalent modifiers in drugs are designed to target the thiol group of cysteine (Gan et al., 2009; Leproult et al., 2011). Quinacrine interact directly with nucleophilic residues in the active site of SARS-CoV-2 3CL pro (e.g. His41 and Met165) which make them highly attractive for covalent interactions. Contrary, suramin interact with Lys and Tyr residues that can also form covalent bonds (Tang et al., 2020), but in a less probability compared with Cys, His and Met.

To study in more detail the plasticity of the virus protease in complex with quinacrine and suramin the consequences on the ligand binding areas, the substrate-binding sites ( $\mathrm{S} 1, \mathrm{~S} 1^{\prime}, \mathrm{S} 2, \mathrm{~S} 3$ ) and the oxyanion hole after MD simulation of the complexes were analysed. Amino acid residues forming the substrate-binding site of SARS-CoV-2 3CL pro and their subsites were described previously (Supplementary Table S1) (Chen et al., 2006; Tang et al., 2020). Fig. 6 describe the changes occurred on SARS-CoV-2 3CL pro substrate-binding site caused by the interaction of the inhibitors. MD simulations revealed possible mode of interaction of quinacrine with SARS-CoV-2 $3 \mathrm{CL}^{\text {pro }}$. Thereby, His41, one amino acid residue of the catalytic dyad, interact with quinacrine, this interaction is responsible to block partially the S1 and S3 sites occupying completely the S2 subsite (Fig. 6). Four residues of the protease S2 subsite interact directly with quinacrine via hydrophobic interactions (His41, Met49, Asp187 and Arg188) and two residues of the S3 subsite form H-bonds with the inhibitor molecule (Met165 and Gln189). In the case of suramin, no single amino acid residue of the $\mathrm{S} 1, \mathrm{~S} 1$, $\mathrm{S} 2$ and $\mathrm{S} 3$ subsites are in interaction with the ligand, which agrees with the results of the activity assay that describe suramin as non-competitive inhibitor of SARS-CoV-2 $3 C L^{\text {pro }}$. 
bioRxiv preprint doi: https://doi org/10.1101/2020.11.11.378018; this version posted November $12,2020$. The copyright holder for this preprint (which was not certified by peer review) is the author/funder, who has granted bioRxiv a license to display the preprint in perpetuity. It is made available under aCC-BY-NC-ND 4.0 International license.

Figure 6

Fig. 6. Substrate-binding pocket and oxyanion hole of SARS-CoV-2 3CL $\mathrm{CL}^{\text {pro }}\left(\mathrm{S1}, \mathrm{S} 1^{\prime}, \mathrm{S2}, \mathrm{S3}\right)$ free accessibility and under the influence of quinacrine and suramin. Structural overlay between the single protein and in complex, the active site residues are highlighted. The amino acid residues are shown in sticks. The surface view (zoom) of the substrate-binding area demonstrates the occupied area by the molecules and the conformational changes induced by its binding. Substrate-binding subsites highlighted as green S1; gold S1; red S2 and blue S3.

Suramin binds allosterically and the ligand interaction induces conformational changes in the catalytic site (most observable for subsites S1` and S2), thus preventing the entry and the turnover of the substrate (Fig. 7). Additionally, the volume of the active site pocket decreased considerably after suramin binding, even whether the molecule was docking just in protomer 1, changing the volume of the pocket from 261 to $90 \AA^{3}$ (Protomer 1) and to 120 (Protomer 2) (Fig. 7C to E).

\section{Figure 7}

Fig. 7. Comparison of SARS-CoV-2 3CL pro with and without suramin after MD simulation. Protomer 1 is colored in turquois, protomer 2 in grey and active site pocket volume in violet. Red arrows highlight a conformational change in the SARS-CoV-2

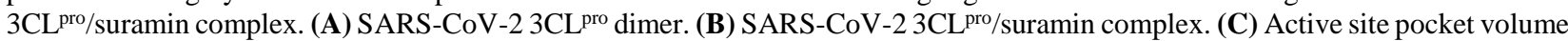
of SARS-CoV-2 3CL pro, substrate-binding subsites are highlighted as green S1; gold S1; red S2 and blue S3. (D) Active site pocket volume of protomer 2. (E) Active site pocket volume of protomer 1.

\subsection{Suramin and quinacrine act cooperatively to inhibit SARS-CoV-2 3CL ${ }^{\text {pro }}$}

Suramin and quinacrine, as described previously, bind in different regions of SARS-CoV-2 $3 \mathrm{CL}^{\text {pro }}$.To conjecture about the effect of both molecules simultaneously, we performed a combined inhibitory assay, whither both molecules were mixed (1:1) and tested against SARS-CoV-2 3CL ${ }^{\text {pro }}$ (Fig. 8).

\section{Figure 8}

Fig. 8. SARS-CoV-2 3CL pro inhibition by a combination of quinacrine and suramin. (A) Ribbon representation of the SARSCoV-2 3CL pro model (grey/cyan) (PDB entry: 6M2Q) in complex with suramin and quinacrine (sticks in orange). (B) Normalized activity and inhibition of SARS-CoV-2 $3 \mathrm{CL}^{\text {pro }}$ under quinacrine and suramin influence.

The inhibition assay was performed with a solution containing both ligands (suramin and quinacrine) with the molar ratio of $1: 1$. The calculated $\mathrm{IC}_{50}$ value $(0.46 \pm 0.1 \mu \mathrm{M})$ demonstrated an increased inhibition capacity of the drugs (Table 5 and supplementary Fig. S11). When compared with the single molecules, the combination enhances the inhibitory capacity of the studied drugs for approx. 10 times. Which could be observed by the determined $\mathrm{IC}_{50}$ values. We assume that the conformational changes after suramin interaction with SARS-CoV-2 $3 \mathrm{CL}^{\text {pro }}$ induce a structural 
change in both active sites in the dimer, which could make them more accessible for the interaction with quinacrine (Fig. 7).

\section{Conclusions}

In summary, the cooperative inhibition of quinacrine and suramin could lead to a possible alternative to combat COVID-19 infections. Repurposing of clinically developed drugs is a common procedure to combat fast evolving pathogens. Similar studies addressed the use of established drugs against SARS-CoV-2 (e.g. Boceprevir, Menadione and Disulfiram) (Ma et al., 2020; He et al., 2020; Jin et al., 2020). (Table 5). The 1:1 combination of quinacrine and suramin possess an effective anti-3CL ${ }^{\text {pro }}$ activity, demonstrating the potential of repurposing drugs to stop the replication process of SARS-CoV-2.

\begin{tabular}{|c|c|c|}
\hline Compound & $\mathrm{IC}_{50}[\mu \mathrm{M}]$ & Reference \\
\hline Quinacrine & $7.8 \pm 0.9$ & reported here \\
\hline Suramin & $6.3 \pm 0.8$ & reported here \\
\hline $\begin{array}{l}\text { Quinacrine + } \\
\text { Suramin }\end{array}$ & $0.46 \pm 0.1$ & reported here \\
\hline Boceprevir & $4.14 \pm 0.61$ & Ma et al., 2020 \\
\hline Narlaprevir & $5.73 \pm 0.67$ & Ma et al., 2020 \\
\hline Simeprevir & $13.74 \pm 3.75$ & Ma et al., 2020 \\
\hline Auranofin & $0.51 *$ & He et al., 2020 \\
\hline Menadion & $7.96^{*}$ & He et al., 2020 \\
\hline Ebselen & $0.67 \pm 0.06$ & Jin et al., 2020 \\
\hline Disulfiram & $9.35 \pm 0.18$ & Jin et al., 2020 \\
\hline Tideglusib & $1.55 \pm 0.30$ & Jin et al., 2020 \\
\hline Carmofur & $1.82 \pm 0.06$ & Jin et al., 2020 \\
\hline
\end{tabular}

* He et al. 2020 without standard deviation. 


\section{Competing interests}

The authors declare that they have no competing interests.

\section{Acknowledgements}

We would like to thank members of the Multiuser Center for Biomolecular Innovation (IBILCE,

São Jose do Rio Preto, Brazil) and the Institute of Biological Information Processing (Forschungszentrum Jülich, Germany), without whose help this project would have not been feasible. This research was supported by grants from CNPq [Grant numbers 435913/2016-6, 401270/2014-9, 307338/2014-2], FAPESP [Grant numbers 2016/12904-0, 2018/12659-0 2018/07572-3, 2019/05614-3], FUNDECT [23/200.307/2014], MOI III, CAPES and PROPe UNESP. This study was supported in part by the UFMS/MEC-Brasil and UFT/MEC-Brasil.

\section{Authors' contributions}

M.A.C. and R.J.E conceived, designed, performed and analyzed the experiments of SARS-CoV$23 \mathrm{CL}^{\text {pro }}$ in complex with Quinacrine and Suramin. D.S.O. and M.S.A. performed the docking and MD simulations. D.S.O., M.A.C, and R.J.E performed the docking and MD simulation analysis. R.K.A. and D.W. guided the research and the elaboration of the manuscript. R.J.E. and M.A.C. coordinated the research and wrote the manuscript. All authors read and took part in revising the final manuscript version.

\section{References}

Ahumada, M., Lissi, E., Montagut, A.M., Valenzuela-Henríquez, F., Pacioni, N.L., Alarcon, E.I., 2017. Association models for binding of molecules to nanostructures. Analyst. 142, 20672089. https://doi.org/10.1039/C7AN00288B

Anand, K., Palm, G.J., Mesters, J.R., Siddell, S.G., Ziebuhr, J., Hilgenfeld, R., 2002. Structure of coronavirus main proteinase reveals combination of a chymotrypsin fold with an extra $\alpha$ helical domain. EMBO J. 21, 3213-3224. https://doi.org/10.1093/emboj/cdf327 
Anand, K., Ziebuhr, J., Wadhwani, P., Mesters, J.R., Hilgenfeld, R., 2003. Coronavirus main proteinase (3CLpro) structure: basis for design of anti-SARS drugs. Science. 300, 1763-1767. https://doi.org/10.1126/science.1085658

Berg, J.M., Tymoczko, J.L., Stryer, L., 2002. Section 8.4-The Michaelis-Menten Model Accounts for the Kinetic Properties of Many Enzymes. Biochemistry, fifth ed. WH Freeman, New York. Available from: http://www. ncbi. nlm. nih. gov/books/NBK22430.

Burch, T.A., Ashburn, L.L., 1951. Experimental therapy of onchocerciasis with suramin and hetrazan; results of a three-year study. Am. J. Trop. Med. Hyg. 31, 617-623. https://doi.org/10.4269/ajtmh.1951.s1-31.617

Case, D.A., Cerutti, D.S., Cheatham, III T.E., Darden, T.A., Gohlke, H., Luo, R., Merz, K.M., Onufriev, A., Simmerling, C., Wang, B., Woods, R.J., 2005. The Amber biomolecular simulation programs. J. Comput. Chem. 26, 1668-1688. https://doi.org/10.1002/jcc.20290

Case, D.A., Cerutti, D.S., Cheatham, III T.E., Darden, T.A., Duke, R.E., Giese, T.J., Giambasu, G., Gilson, M.K., Gohlke, H., Goetz, A.W., Harris, R., Izadi, S., Izmailov, S.A., Kasavajhala, K., Kovalenko, A., Krasny, R., Kurtzman, T., Lee, T.S., LeGrand, S., Li, P., Lin, C., Liu, J., Luchko, T., Luo, R., Man, V., Merz, K.M., Miao, Y., Mikhailovskii, O., Monard, G., Nguyen, H., Onufriev, A., Pan, F., Pantano, S., Qi, R., Roe, D.R., Roitberg, A., Sagui, C., SchottVerdugo, S., Shen, J., Simmerling, C.L., Skrynnikov, N.R., Smith, J., Swails, J., Walker, R.C., Wang, J., Wilson, L., Wolf, R.M., Wu, X., Xiong, Y., Xue, Y., York, D.M., Kollman, P.A. AMBER 2018 University of California, San Francisco.

Catici, D.A., Amos, H.E., Yang, Y., van den Elsen, J.M., Pudney, C.R., 2016. The red edge excitation shift phenomenon can be used to unmask protein structural ensembles: implications for NEMO-ubiquitin interactions. FEBS J. 283, 2272-2284. https://doi.org/10.1111/febs.13724

Chen, H., Wei, P., Huang, C., Tan, L., Liu, Y., Lai, L., 2006. Only one protomer is active in the dimer of SARS 3C-like proteinase. J. Biol. Chem. 281, 13894-13898. https://doi.org/10.1074/jbc.M510745200

Chen, Y., Liu, Q., Guo, D., 2020. Emerging coronaviruses: genome structure, replication, and pathogenesis. J. Med. Virol. 92, 418-423. https://doi.org/10.1002/jmv.25681

Coronado, M.A., Eberle, R.J., Bleffert, N., Feuerstein, S., Olivier, D.S., de Moraes, F.R., Willbold, D., Arni, R.K., 2018. Zika virus NS2B/NS3 proteinase: A new target for an old drug-Suramin 
a lead compound for NS2B/NS3 proteinase inhibition. Antiviral Res. 160, 118-125. https://doi.org/10.1016/j.antiviral.2018.10.019

da Silva, C.S.B., Thaler, M., Tas, A., Ogando, N.S., Bredenbeek, P.J., Ninaber, D.K., Wang, Y.,

Hiemstra, P.S., Snijder, E.J., van Hemert, M.J., 2020. Suramin inhibits SARS-CoV-2 infection in cell culture by interfering with early steps of the replication cycle. Antimicrob. Agents Chemother. 64, e00900-20. https://doi.org/10.1128/AAC.00900-20

Darden, T., York, D., Pedersen, L., 1993. Particle mesh Ewald: An N· log (N) method for Ewald sums in large systems. J. Chem. Phys. 98, 10089.

de Wit, E., Feldmann, F., Cronin, J., Jordan, R., Okumura, A., Thomas, T., Scott, D., Cihlar, T., Feldmann, H., 2020. Prophylactic and therapeutic remdesivir (GS-5734) treatment in the rhesus macaque model of MERS-CoV infection. PNAS. 117, 6771-6776. https://doi.org/10.1073/pnas.1922083117

Duan, X., Han, Y., Yang, L., Nilsson, B., Wang, P., Zhang, T., Xiang, J., Xu, D., Wang, X., Uhl, S., Huang, Y., Chen, H.J., Wang, H., tenOever, B., Schwartz, R.E., Ho, D.D., Evans, T., Pan, F.C., Chen, S., 2020. Identification of Drugs Blocking SARS-CoV-2 Infection using Human Pluripotent Stem Cell-derived Colonic Organoids. bioRxiv. https://doi.org/10.1101/2020.05.02.073320

Frisch, M.J., Trucks, G.W., Schlegel, H.B., Scuseria, G.E., Robb, M.A., Cheeseman, J.R., Scalmani, G., Barone, V., Petersson, G.A., Nakatsuji, H., Li, X., Caricato, M., Marenich, A.V., Bloino, J., Janesko, B.G., Gomperts, R., Mennucci, B., Hratchian, H.P., Ortiz, J.V., Izmaylov, A.F., Sonnenberg, J.L., Williams-Young, D., Ding, F., Lipparini, F., Egidi, F., Goings, J., Peng, B., Petrone, A., Henderson, T., Ranasinghe, D., Zakrzewski, V.G., Gao, J., Rega, N., Zheng, G., Liang, W., Hada, M., Ehara, M., Toyota, K., Fukuda, R., Hasegawa, J., Ishida, M., Nakajima, T., Honda, Y., Kitao, O., Nakai, H., Vreven, T., Throssell, K., Montgomery, J.A. Jr, Peralta, J.E., Ogliaro, F., Bearpark, M.J., Heyd, J.J., Brothers, E.N., Kudin, K.N., Staroverov, V.N., Keith, T.A., Kobayashi, R., Normand, J., Raghavachari, K., Rendell, A.P., Burant, J.C., Iyengar, S.S., Tomasi, J., Cossi, M., Millam, J.M., Klene, M., Adamo, C., Cammi, R., Ochterski, J.W., Martin, R.L., Morokuma, K., Farkas, O., Foresman, J.B., Fox, D.J., 2016. Gaussian, Inc., Gaussian 16, Revision B.01. Wallingford CT.

Gan, J., Ruan, Q., He, B., Zhu, M., Shyu, W.C., Humphreys, W.G., 2009. In vitro screening of 50 highly prescribed drugs for thiol adduct formation — comparison of potential for drug induced toxicity and extent of adduct formation. Chem. Res. Toxicol. 22, 690-698. https://doi.org/10.1021/tx800368n 
Gordon, J.C., Myers, J.B., Folta, T., Shoja, V., Heath, L.S., Onufriev, A., 2005. H++: a server for estimating pKas and adding missing hydrogens to macromolecules. Nucleic Acids Res. 33(Web Server issue), W368-71. https://doi.org/10.1093/nar/gki464

He, Z., Zhao, W., Niu, W., Gao, X., Gao, X., Gong, Y., Gao, X., 2020. Molecules inhibit the enzyme activity of 3-chymotrypsin-like cysteine protease of SARS-CoV-2 virus: the experimental and theory studies. bioRxiv. https://doi.org/10.1101/2020.05.28.120642

Hoekenga, M.T., 1955. The treatment of malaria with hydroxychloroquine. Am. J. Trop. Med. Hyg. 4, 221-223. https://doi.org/10.4269/ajtmh.1955.4.221

Huang, C., Wang, Y., Li, X., Ren, L., Zhao, J., Hu, Y., Zhang, L., Fan, G., Xu, J., Gu, X., Cheng, Z., Yu, T., Xia, J., Wei, Y., Wu, W., Xie, X., Yin, W., Li, H., Liu, M., Xiao, Y., Gao, H., Guo, L., Xie, J., Wang, G., Jiang, R., Gao, Z., Jin, Q., Wang, J., Cao, B., 2020. Clinical features of patients infected with 2019 novel coronavirus in Wuhan, China. Lancet. 395, 497-506. https://doi.org/10.1016/S0140-6736(20)30183-5

Hussain, S., Chen, Y., Yang, Y., Xu, J., Peng, Y., Wu, Y., Li, Z., Zhu, Y., Tien, P., Guo, D., 2005. Identification of novel subgenomic RNAs and noncanonical transcription initiation signals of severe acute respiratory syndrome coronavirus. J. Virol. 79, 5288-5295. https://doi.org/10.1128/JVI.79.9.5288-5295.2005

Jin, Z., Du, X., Xu, Y., Deng, Y., Liu, M., Zhao, Y., Zhang, B., Li X., Zhang, L., Peng, C., Duan, Y., Yu, J., Wang, L., Yang, K., Liu, F., Jiang, R., Yang, X., You, T., Liu, X., Yang, X., Bai, F., Liu, H., Liu, X., Guddat, L.W., Xu, W., Xiao, Q., Qin, C., Shi, Z., Jiang, H., Rao, Z., Yang, H., 2020. Structure of M pro from SARS-CoV-2 and discovery of its inhibitors. Nature. 582, 289-293. https://doi.org/10.1038/s41586-020-2223-y

Johnson, M.L., Frasier, S.G., 1985. Nonlinear least-squares analysis. Meth. Enzymol. 117, 301-42. https://doi.org/10.1016/S0076-6879(85)17018-7

Joy, R.J., 1999. Malaria in American troops in the south and southwest Pacific in World War II. Med. Hist. 43, 192-207. https://doi.org/10.1017/s002572730006508x

Lai, C.C., Shih, T.P., Ko, W.C., Tang, H.J., Hsueh, P.R., 2020. Severe acute respiratory syndrome coronavirus 2 (SARS-CoV-2) and corona virus disease-2019 (COVID-19): the epidemic and the challenges. Int. J. Antimicrob. Agents. 55, 105924. https://doi.org/10.1016/j.ijantimicag.2020.105924 
Leproult, E., Barluenga, S., Moras, D., Wurtz, J.M., Winssinger, N., 2011. Cysteine mapping in conformationally distinct kinase nucleotide binding sites: application to the design of selective covalent inhibitors. J. Med. Chem. 54, 1347-1355. https://doi.org/10.1021/jm101396q

Liu, J., Cao, R., Xu, M., Wang, X., Zhang, H., Hu, H., Li, Y., Hu, Z., Zhong, W., Wang, M., 2020. Hydroxychloroquine, a less toxic derivative of chloroquine, is effective in inhibiting SARSCoV-2 infection in vitro. Cell Discov. 6, 1-4. https://doi.org/10.1038/s41421-020-0156-0

Lu, H., Stratton, C.W., Tang, Y.W., 2020. Outbreak of pneumonia of unknown etiology in Wuhan, China: The mystery and the miracle. J. Med. Virol. 92, 401-402. https://doi.org/10.1002/jmv.25678

Ma, C., Sacco, M.D., Hurst, B., Townsend, J.A., Hu, Y., Szeto, T., Zhang, X., Tarbet, B., Marty, M.T., Chen, Y., Wang, J., 2020. Boceprevir, GC-376, and calpain inhibitors II, XII inhibit SARS-CoV-2 viral replication by targeting the viral main protease. Cell Res. 30, 678-692. https://doi.org/10.1038/s41422-020-0356-Z

Möller, M., Denicola, A., 2002. Protein tryptophan accessibility studied by fluorescence quenching. Biochem. Mol. Biol. Edu. 30, 175-178. https://doi.org/10.1002/bmb.2002.494030030035

Motulsky, H., Christopoulos, A., 2004. Fitting models to biological data using linear and nonlinear regression: a practical guide to curve fitting. Oxford University Press.

Nga, P.T., del Carmen Parquet, M., Lauber, C., Parida, M., Nabeshima, T., Yu, F., Thuy, N.T., Inoue, S., Ito, T., Okamoto, K., Ichinose, A., Snijder, E.J., Morita, K., Gorbalenya, A.E., 2011. Discovery of the first insect nidovirus, a missing evolutionary link in the emergence of the largest RNA virus genomes. PLoS Pathog. 7, e1002215. https://doi.org/10.1371/journal.ppat.1002215

Nguyen, H., Roe, D.R., Simmerling, C., 2013. Improved generalized born solvent model parameters for protein simulations. J. Chem. Theory Comput. 9, 2020-2034. https://doi.org/10.1021/ct3010485

Pettinger. J., Jones, K., Cheeseman, M.D., 2017. Lysine-targeting covalent inhibitors. Angew. Chem. Int. Ed. 56, 15200-15209. https://doi.org/10.1002/anie.201707630

Pillaiyar, T., Manickam, M., Namasivayam, V., Hayashi, Y., Jung, S.H., 2016. An overview of severe acute respiratory syndrome-coronavirus (SARS-CoV) 3CL protease inhibitors: peptidomimetics and small molecule chemotherapy. J. Med. Chem. 59, 6595-6628. https://doi.org/10.1021/acs.jmedchem.5b01461 
Ramajayam, R., Tan, K.P., Liang, P.H., 2011. Recent development of 3C and 3CL protease inhibitors for anti-coronavirus and anti-picornavirus drug discovery. Biochem. Soc. Trans. 39, 1371-1375. https://doi.org/10.1042/BST0391371

Ren, Z., Yan, L., Zhang, N., Guo, Y., Yang, C., Lou, Z., Rao, Z., 2013. The newly emerged SARSlike coronavirus HCoV-EMC also has an" Achilles' heel": current effective inhibitor targeting a 3C-like protease. Protein Cell. 4, 248-50. https://doi.org/10.1007/s13238-013-2841-3.

Roldan, E.Q., Biasiotto, G., Magro, P., Zanella, I., 2020. The possible mechanisms of action of 4aminoquinolines (chloroquine/hydroxychloroquine) against Sars-Cov-2 infection (COVID19): A role for iron homeostasis? Pharmacol. Res. 158, 104904. https://doi.org/10.1016/j.phrs.2020.104904

Roy, A., Lim, L., Srivastava, S., Lu, Y., Song, J., 2017. Solution conformations of Zika NS2BNS3pro and its inhibition by natural products from edible plants. PloS one. 12, e0180632. https://doi.org/10.1371/journal.pone.0180632

Shaikh, S.M.T., Seetharamappa, J., Ashoka, S., Kandagal, P.B., 2007. A study of the interaction between bromopyrogallol red and bovine serum albumin by spectroscopic methods. Dyes Pigments. 73, 211-216. https://doi.org/10.1016/j.dyepig.2005.11.008

Sreerama, N., Woody, R.W., 2000. Estimation of protein secondary structure from circular dichroism spectra: comparison of CONTIN, SELCON, and CDSSTR methods with an expanded reference set. Anal. Biochem. 287, 252-260. https://doi.org/10.1006/abio.2000.4880

Tang, B., He, F., Liu, D., Fang, M., Wu, Z., Xu, D., 2020. AI-aided design of novel targeted covalent inhibitors against SARS-CoV-2. bioRxiv. https://doi.org/10.1101/2020.03.03.972133

Tian, C., Kasavajhala, K., Belfon, K.A.A., Raguette, L., Huang, H., Migues, A.N., Bickel, J., Wang, Y., Pincay, J., Wu, Q., Simmerling, C., 2020. ff19SB: Amino-Acid-Specific Protein Backbone Parameters Trained against Quantum Mechanics Energy Surfaces in Solution. J. Chem. Theory Comput. 16, 528-52. https://doi.org/10.1021/acs.jctc.9b00591

Trott, O., Olson, A.J., 2010. AutoDock Vina: Improving the speed and accuracy of docking with a new scoring function, efficient optimization, and multithreading. J. Compu. Chem. 31, 455461. https://doi.org/10.1002/jcc. 21334

Steverding, D., 2010. The development of drugs for treatment of sleeping sickness: a historical review. Parasit. Vectors. 3, 15. https://doi.org/10.1186/1756-3305-3-15 
Touret, F., de Lamballerie, X., 2020. Of chloroquine and COVID-19. Antiviral Res. 177, 104762. https://doi.org/10.1016/j.antiviral.2020.104762

Wang, J.M., Wolf, R.M., Caldwell, J.W., Kollman, P.A., Case, D.A., 2004. Development and testing of a general amber force field. J. Comput. Chem. 25, 1157-74. https://doi.org/10.1002/jcc.20035

Wang, J., Wang, W., Kollman, P.A., Case, D.A., 2006. Automatic atom type and bond type perception in molecular mechanical calculations. J. Mol. Graph. Model. 25, 247-60. https://doi.org/10.1016/j.jmgm.2005.12.005

Wang, G., Liu, X., Yan, C., Bai, G., Lu, Y., 2015. Probing the binding of trypsin to glutathionestabilized gold nanoparticles in aqueous solution. Colloids Surf. B Biointerfaces. 135, 261266. https://doi.org/10.1016/j.colsurfb.2015.07.063

Way, J.C., 2000. Covalent modification as a strategy to block protein-protein interactions with small-molecule drugs. Curr. Opin. Chem. Biol. 4, 40-46. https://doi.org/10.1016/S13675931(99)00049-6

WHO. 2020. World Health Organization, Coronavirus disease 2019 (COVID-19) Dashboard, 11.11.2020.

Wu, Q.Y., Jiang, L.L., Yang, S.G., Zuo, Y., Wang, Z.F., Xi, Z., Yang, G.F., 2014. Hexahydrophthalimide-benzothiazole hybrids as a new class of protoporphyrinogen oxidase inhibitors: synthesis, structure-activity relationship, and DFT calculations. New J. Chem. 38, 4510-4518. https://doi.org/10.1039/C4NJ00636D

Wu, F., Zhao, S., Yu, B., Chen, Y.M., Wang, W., Song, Z.G., Hu, Y., Tao, Z.W., Tian, J.H., Pei, Y.Y., Yuan, M.L., Zhang, Y.L., Dai, F.H., Liu, Y., Wang, Q.M., Zheng, J.J., Xu, L., Holmes, E.C., Zhang, Y.Z., 2020. A new coronavirus associated with human respiratory disease in China. Nature. 579, 265-269. https://doi.org/10.1038/s41586-020-2008-3

Yang, H., Yang, M., Ding, Y., Liu, Y., Lou, Z., Zhou, Z., Sun, L., Mo, L., Ye, S., Pang, H., Gao, G.F., Anand, K., Bartlam, M., Hilgenfeld, R., Rao, Z., 2003. The crystal structures of severe acute respiratory syndrome virus main protease and its complex with an inhibitor. PNAS. 100, 13190-13195. https://doi.org/10.1073/pnas.1835675100

Yu, J., Zhou, Y., Tanaka, I., Yao, M., 2010. Roll: A new algorithm for the detection of protein pockets and cavities with a rolling probe sphere. Bioinformatics. 26, 46-52. https://doi.org/10.1093/bioinformatics/btp599 
Zhang, J.H., Chung, T.D.Y., Oldenburg, K.R., 1999. A simple statistical parameter for use in evaluation and validation of high throughput screening assays. J. Biomol. Screen. 4, 67-73. https://doi.org/10.1177/108705719900400206

Zhang, L., Lin, D., Sun, X., Curth, U., Drosten, C., Sauerhering, L., Becker, S., Rox, K., Hilgenfeld, R., 2020a. Crystal structure of SARS-CoV-2 main protease provides a basis for design of $\begin{array}{lllll}\text { improved } \quad \alpha \text {-ketoamide } \quad \text { inhibitors. } & \text { Science. }\end{array}$ https://doi.org/10.1126/science.abb3405

Zhang, L., Lin, D., Kusov, Y., Nian, Y., Ma, Q., Wang, J., De Wilde, A., 2020b. $\alpha$-Ketoamides as broad-spectrum inhibitors of coronavirus and enterovirus replication: Structure-based design, synthesis, and activity assessment. J. Med. Chem. 63, 4562-4578. https://doi.org/10.1021/acs.jmedchem.9b01828 

B

A

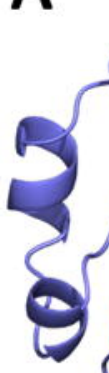

लिक

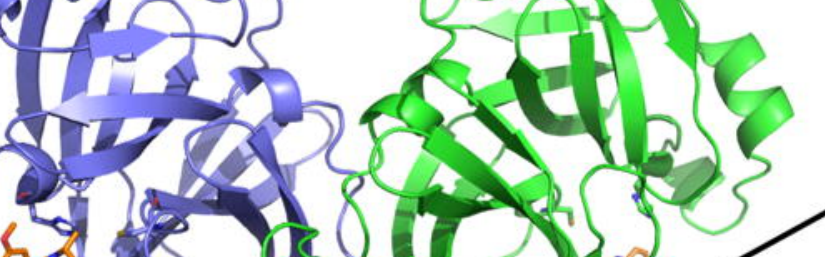
-
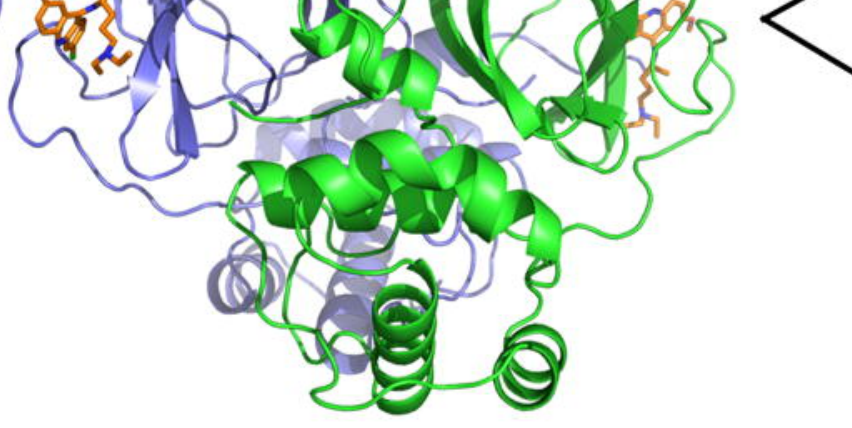

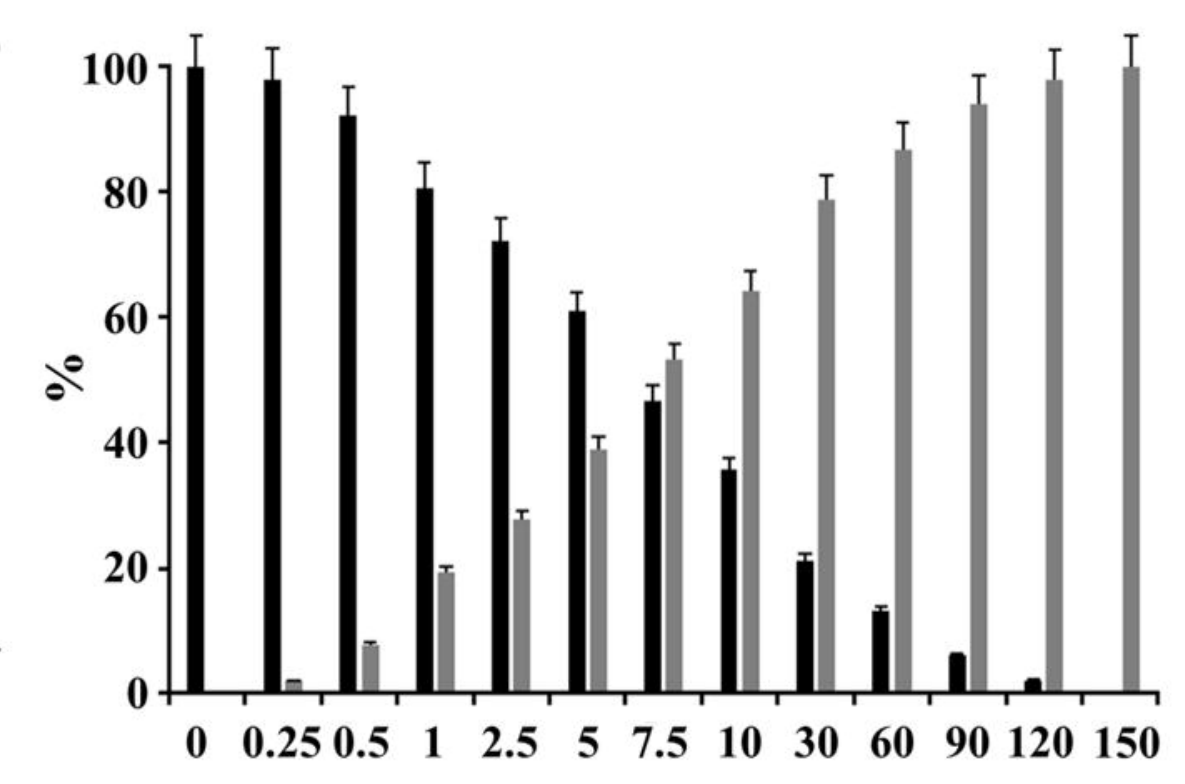

- Activity

- Inhibition

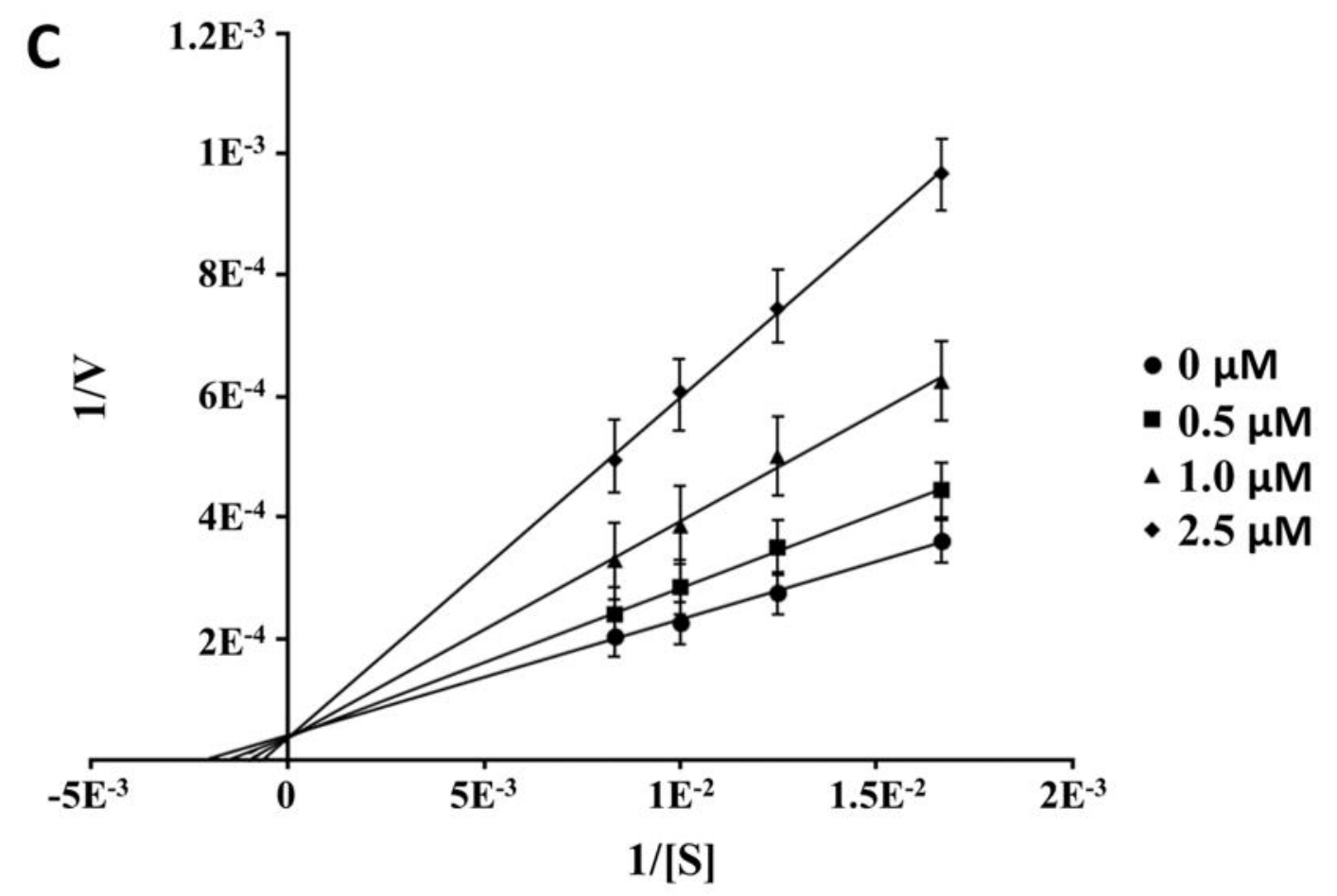


A

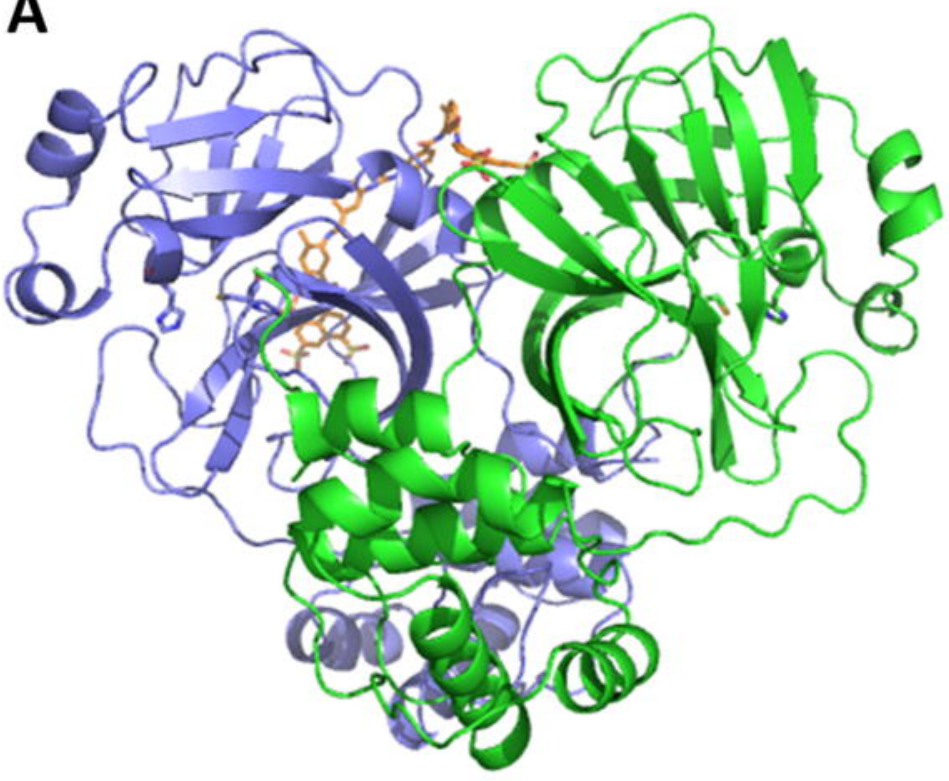

$\begin{array}{ll}\text { B } & 100 \\ 80 \\ \\ 0\end{array}$ 


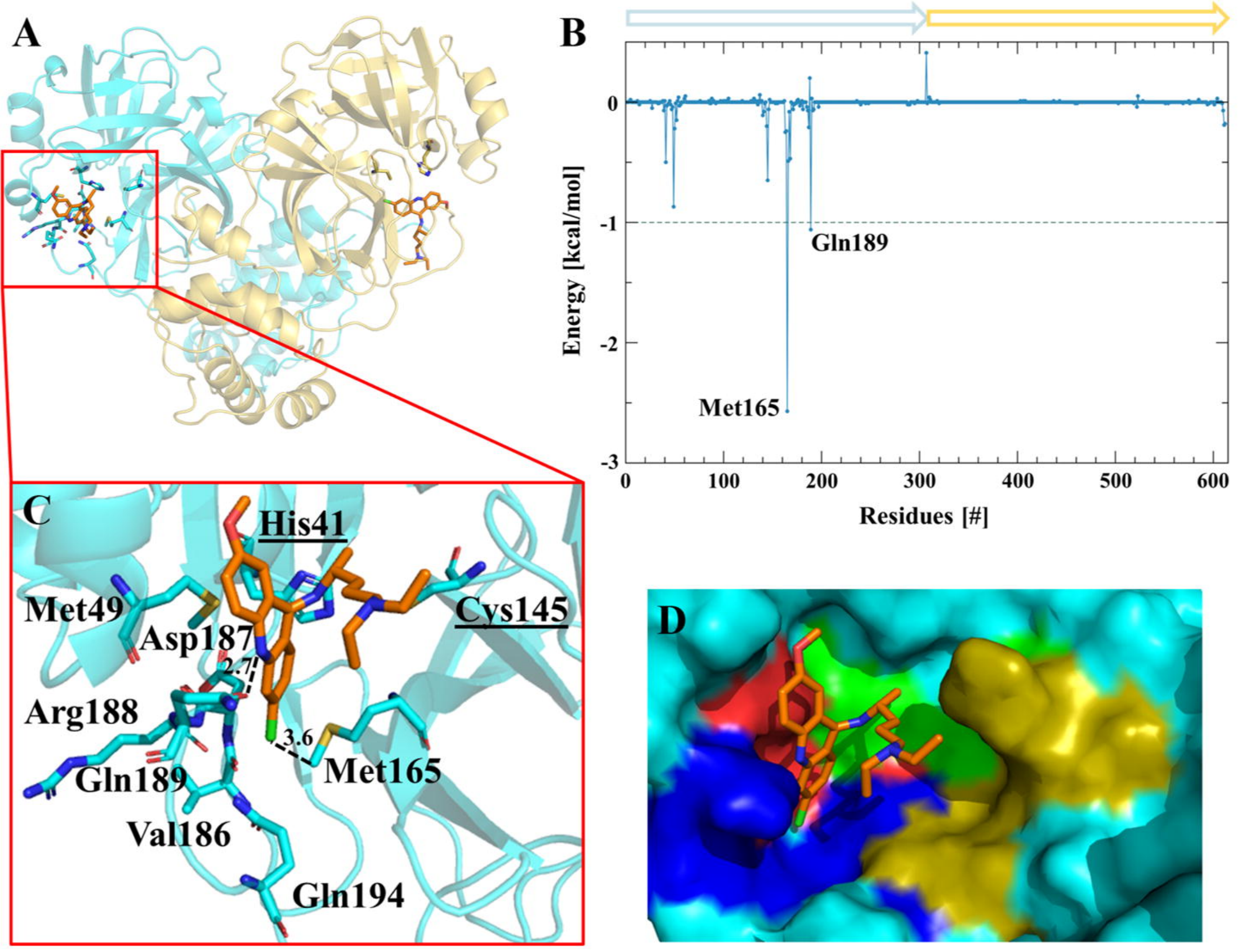




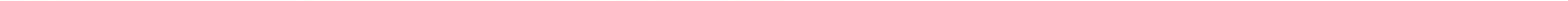


SARS-CoV2-3CL pro $^{\text {pro }}$
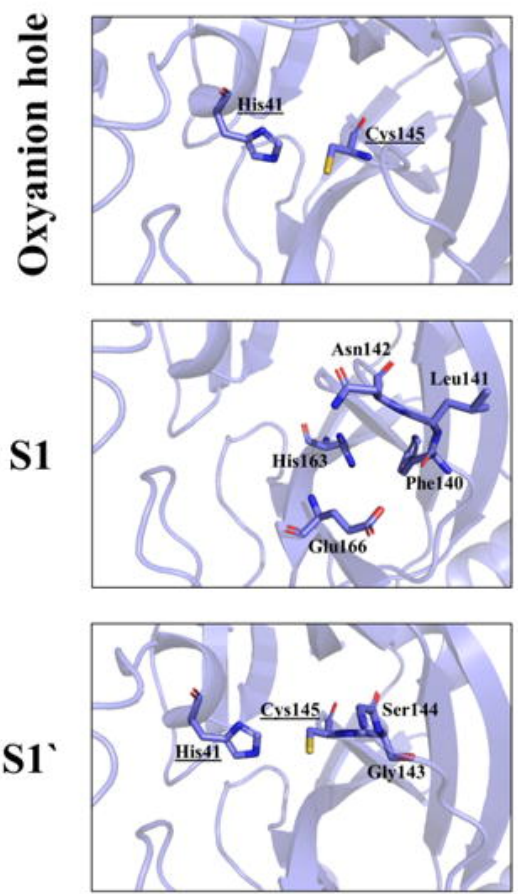

S2
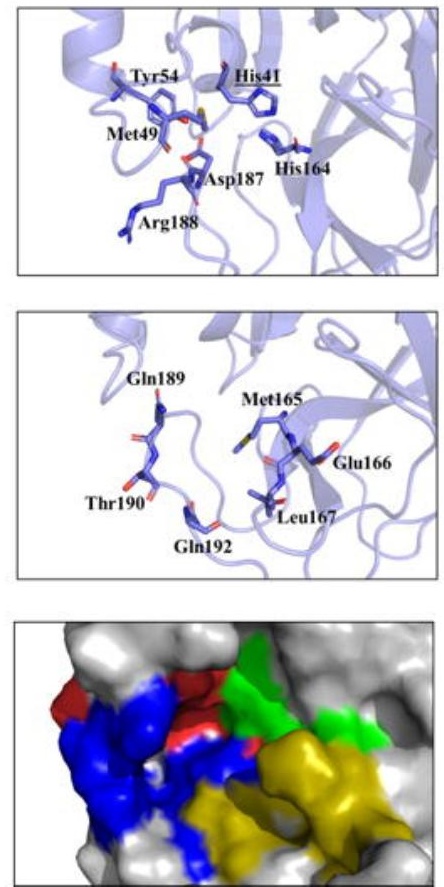

Quinacrine
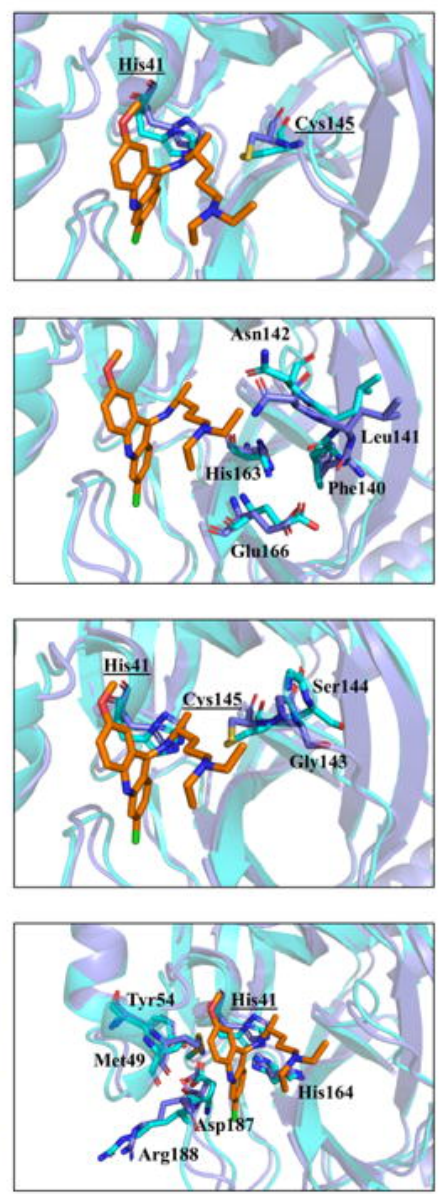

S3
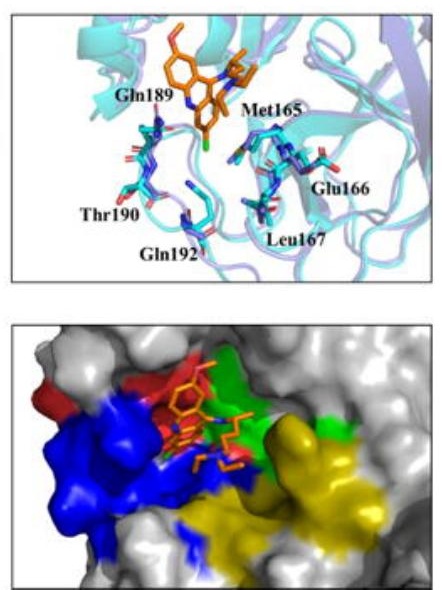

Suramin
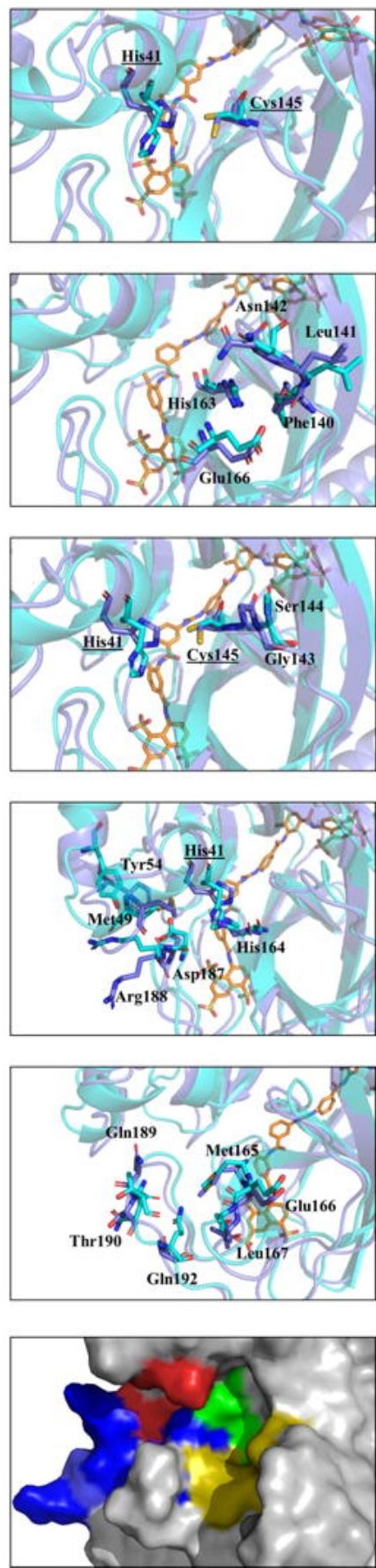
A

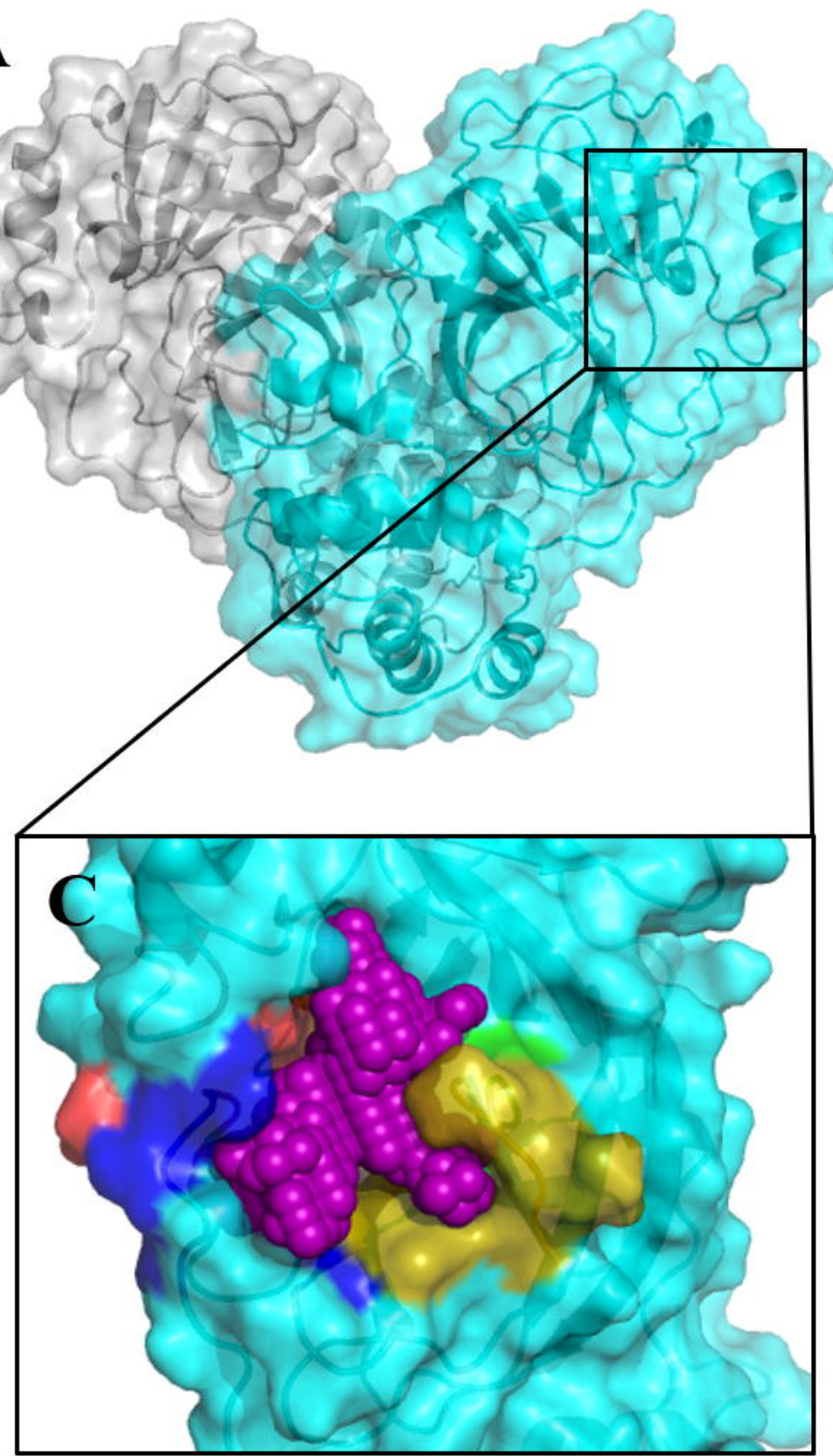

Volume: $261 \AA^{3}$
B

$\langle\langle\vec{b}\rangle \Rightarrow \Rightarrow$
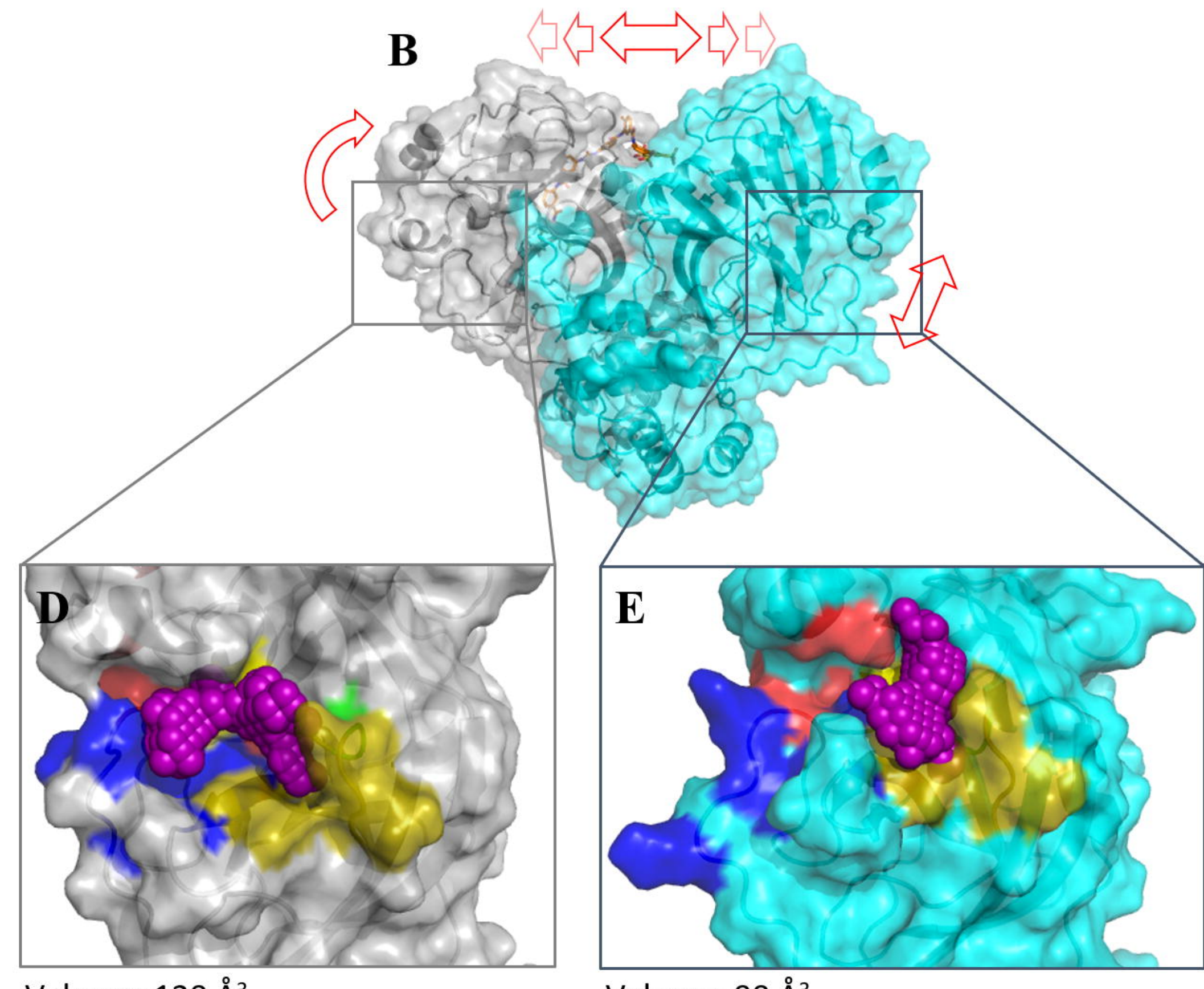

Volume: $90 \AA^{3}$ 


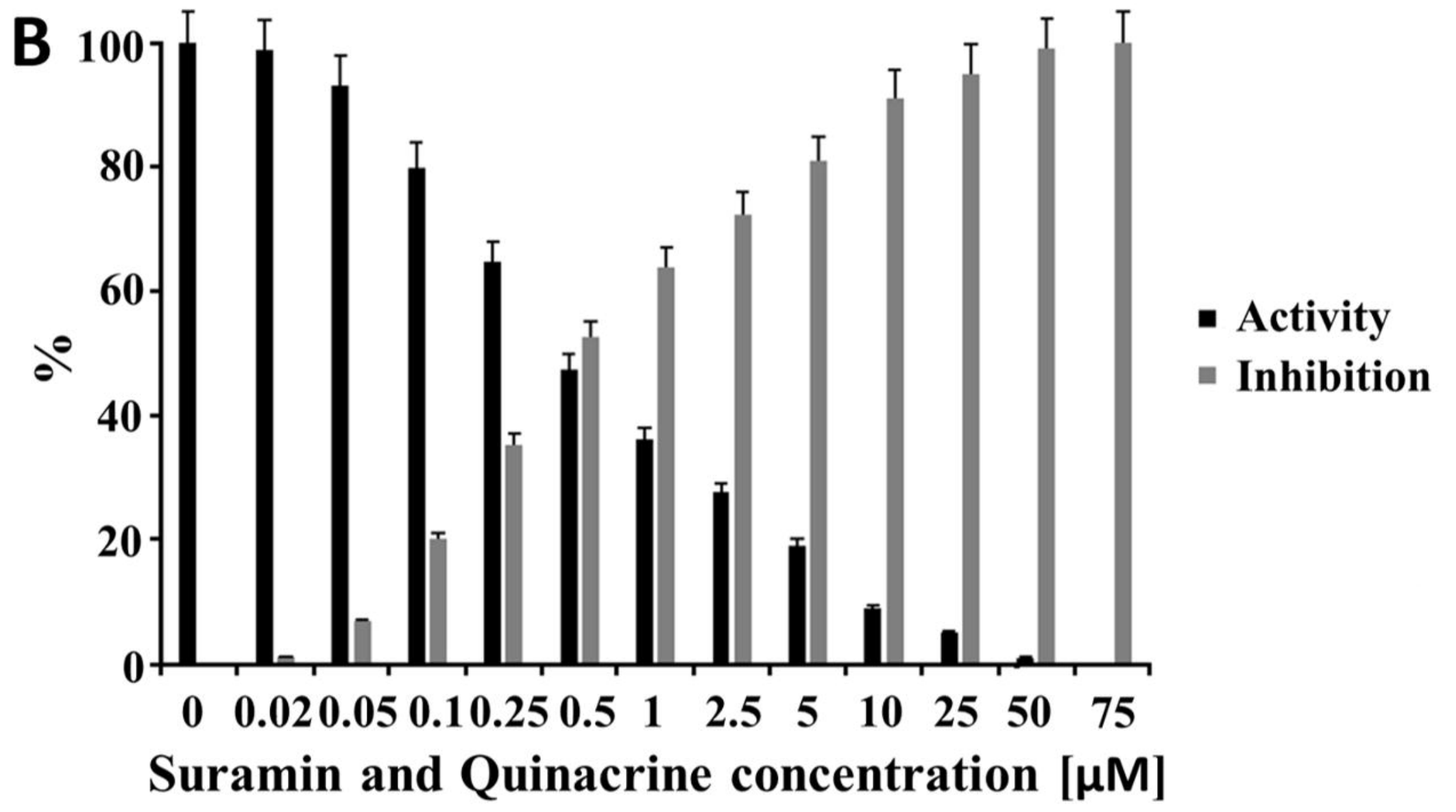

